\title{
La entrevista libre como método para evitar la paradoja del observador Un estudio de corpus
}

\author{
Alba Fernández Sanmartín \\ Universidade de Santiago de Compostela
}

\begin{abstract}
Observer's paradox has been pointed out as the main problem when it comes to gathering oral materials in an informal colloquial register. The free interview has been proposed as an alternative to the traditional one, where the objective is to minimize the effects of the paradox, through methodology based in the relaxation of the question-answer structure, interviewer-interviewee distance and differentiated roles. The objective of this study is to carry out a lexical corpus analysis, in order to show the influence of the observer's paradox on the materials obtained through interviews, and to evaluate if the strategies of the free interview are effective in obtaining a register similar to that of a conversation.
\end{abstract}

Keywords: sociolinguistic interview, observer's paradox, register, conversation, corpus.

\section{Introducción}

Desde que, a mediados del siglo pasado, comenzaron a dejarse atrás los prejuicios teóricos en cuanto al estudio de la lengua real, el registro oral coloquial se ha erigido como el objeto de interés fundamental de los estudios de la lengua en su contexto, por ser el más empleado por los hablantes, aquel en el que menos actúa la conciencia metalingüística y en el que más claramente se aprecian los procesos de cambio de la lengua.

Sin embargo, el estudio de este registro plantea considerables escollos metodológicos, que atañen fundamentalmente a la dificultad que supone obtener muestras reales para el análisis. La grabación secreta presenta problemas éticos, además de dificultades técnicas, y cualquier otra metodología de obtención de materiales (observación participante, entrevista, grupo de discusión etc.), supone enfrentarse al obstáculo denominado paradoja del observador. ${ }^{1}$

\footnotetext{
${ }^{1}$ Las nuevas tecnologías abren la posibilidad de acceder a otro tipo de materiales conversacionales sin intervención del investigador, salvando, pues, la paradoja del observador. Se trataría de lo que De Benito Moreno \& Estrada (2016: 5) denominan "conversaciones virtuales", es decir, interacciones mediadas por ordenadores o dispositivos electrónicos. Los
} 
De entre todos los métodos existentes, la entrevista ha ocupado, y todavía ocupa, un lugar central en la sociolingüística. Labov, pionero de la técnica (1984), la señaló en su momento como el único medio de obtener el volumen y calidad de grabación de habla necesarios para el análisis cuantitativo. Décadas más tarde la entrevista conserva su lugar preponderante, entre otros motivos porque, como señalan López Morales (1994: 75) o Recalde \& Vázquez Rozas (2009: 56), se trata de un instrumento que permite recoger una gran cantidad de información variada y estratificada en relativamente poco tiempo y con un despliegue razonable de medios y esfuerzos.

Sin embargo, igual que cualquier otra metodología que implique la presencia del investigador y/o un instrumento de grabación visible, la entrevista tiene una grave limitación, que el propio Labov $(1972,1984)$ denominó paradoja del observador. Para este autor, se trata de la materialización de un problema metodológico clásico de los estudios del lenguaje en su contexto social: los medios empleados para la recogida de datos interfieren, condicionan o modifican las características de esos mismos datos. En la entrevista sociolingüística existe, pues, una contradicción entre el tipo de materiales que se desean obtener y el método empleado para hacerlo: la situación de entrevista (un encuentro transaccional entre hablantes desconocidos en un contexto académico) dista mucho de ser la propicia para obtener producciones en un registro relajado y espontáneo.

Por este motivo, numerosos autores, comenzando por el propio Labov, han ido proponiendo recursos destinados a restar formalidad al encuentro $y$, consecuentemente, también al registro empleado en él.

Labov (1972) comenzó por tratar de identificar, dentro de la entrevista, los contextos que motivan el mínimo de atención sobre el lenguaje y, por tanto, el surgimiento del habla casual. Dichos contextos son: el habla sobre juegos de la infancia y sobre el peligro de muerte, la interacción con el entrevistador fuera del

materiales más interesantes en este sentido, por su cercanía a la conversación oral coloquial, serían los que De Benito Moreno \& Estrada (2016: 5-6) engloban en el subtipo de interacciones "cerradas" y "sincrónicas", que son aquellas que se establecen mediante mensajes privados, normalmente entre personas pertenecientes a un círculo cercano, y que buscan el retorno dentro de un periodo relativamente reducido de tiempo. Entrarían dentro de este apartado las conversaciones de Whatsapp o las que tienen lugar a través del chat privado de Facebook. Sin embargo, este tipo de interacciones, aunque presenten puntos en común con la lengua conversacional oral, tienen también características propias determinadas por las circunstancias particulares de su producción. Los materiales correspondientes constituyen, pues, un nuevo y diferente objeto de estudio, no una solución para la problemática que se está presentando en este trabajo. 
formato de entrevista, el discurso dirigido a una tercera persona, y las intervenciones que no responden directamente a una pregunta. Una vez identificados los contextos en que surge habla casual, el segundo paso consiste en favorecerlos, o incluso forzarlos mediante estrategias.

Silva-Corvalán (1989: 25-26) es menos específica, y simplemente apunta que para lograr lo que ella denomina «conversación grabada», el investigador debe poner en práctica «los recursos necesarios para lograr que el hablante olvide que está siendo grabado», para que desvíe la atención de su habla y reduzca la autoobservación y la autocorrección, «fenómenos característicos del estilo formal».

Wolfran \& Fasold (1997: 101-2) proponen una serie de consejos regidos por el «sentido común» para lograr lo que denominan «entrevista espontánea». Según estos autores, resulta beneficioso adaptar las preguntas a los intereses de los hablantes, sobre todo como un medio para lograr su implicación emocional en el discurso y lograr así desviar su atención sobre el propio modo de hablar.

Milroy \& Gordon (2003: 65) consideran también fundamental lograr la implicación emocional del hablante en los temas tratados, y añaden que resulta beneficioso modificar la dinámica tradicional de la entrevista, por ejemplo, planteando entrevistas múltiples.

Vázquez Veiga (2003: 24-25), por su parte, apunta que el entrevistador debe dominar técnicas destinadas a «reducir el grado de formalidad» de las entrevistas, cuidando para ello determinados aspectos de su conducta. La autora pone especial énfasis en los aspectos formales, y señala que el entrevistador debe emplear un modo de expresión lo más sencillo posible, evitando los cultismos y las «construcciones retorcidas».

Hernández Campoy \& Almeida (2005: 136, 144) ponen el acento en el aspecto temático, y señalan que el informante tiene que sentirse «directa e incluso íntimamente involucrado en la narración» para poder relajarse y desviar la atención del tipo de situación en el que se encuentra. Esto suele lograrse a través de temas cotidianos relacionados con el pasado, como anécdotas ocurridas en el colegio, las características del vecindario de su infancia o los primeros noviazgos. Apuntan también la importancia de que el entrevistador rebaje el control sobre la interacción y la deje fluir de manera natural, reduciendo la distancia con el informante.

Vida Castro (2007: 37) apunta en esta última dirección, destacando la importancia de que el entrevistador no someta el intercambio a un guion rígido, sino que lo deje fluir por sus cauces naturales, de modo que el informante se sienta lo más cómodo y libre posible. 
Pitkowski (2010: 82) señala que la espontaneidad del diálogo depende en gran medida de la «habilidad del investigador para establecer y crear una atmósfera cómoda, amistosa y de empatía», y propone otra estrategia para lograr centrar la atención del entrevistado en el contenido y relajar la expresión, que consiste en el posicionamiento del entrevistador en un lugar de desconocimiento respecto al informante sobre algún tema en cuestión.

Moreno Fernández (2011: 6, 8), por último, insiste en que la clave está en provocar una reducción de la monitorización, y una relajación de la tensión causada por la situación de entrevista. Para ello, señala una doble vía: la selección de los temas tratados durante el intercambio y la modificación del marco interactivo.

Como se puede observar, los intentos de modificar el evento de entrevista para tratar de acercarlo a otro más propicio para el surgimiento del vernáculo han existido desde el mismo momento en que comenzó a emplearse la entrevista como técnica de recolección de materiales.

Sin embargo, ninguno de los autores citados presenta pruebas empíricas de que la puesta en práctica de las medidas que proponen resulte en un acercamiento real de los materiales resultantes al registro informal de la conversación, sino que en el mejor de los casos se limitan a señalar que las muestras obtenidas tienen «apariencia» conversacional. Vázquez Veiga (2003: 23), por ejemplo, asegura que en el corpus de lengua hablada de la ciudad de A Coruña, efectuado mediante entrevistas, se obtuvieron muestras de habla «que nos atrevemos a decir que se podrían recoger en cualquier conversación ordinaria». Sin embargo, no apoya tal afirmación con datos reales que contrasten sus materiales con otros prototípicamente conversacionales.

Por otra parte, casi desde el mismo momento en que se comenzaron a proponer este tipo de medidas, empezaron a surgir también críticas dirigidas a ellas. La principal representante de esta postura contraria a la desestructuración de la entrevista es Nessa Wolfson (1976, 1997), que señala que la entrevista libre, desestructurada, no es realmente un evento de habla, sino una especie de híbrido creado ad hoc que no sigue las normas de ningún evento reconocido por el informante. Esta circunstancia puede dificultar la interacción, ya que, al carecer de modelos y referencias, el entrevistado puede experimentar desorientación e incomodidad.

En resumen, aunque este ha sido un tema que ha preocupado a los autores desde la década de los 70, no se han hecho estudios exhaustivos que muestren, por un lado, la influencia de la paradoja del observador en el registro empleado en las entrevistas sociolingüísticas, ni tampoco que prueben si las estrategias que 
tratan de evitarla son efectivas para desformalizar el registro y acercarlo al de la conversación.

Dado este contexto, el objetivo del trabajo es aportar datos que contribuyan a aclarar la cuestión, mostrar las diferencias existentes entre el registro empleado en los distintos tipos de entrevista y en la conversación, y determinar la distancia que separa cada uno de ellos del utilizado en una situación prototípicamente formal.

A continuación, en el apartado 2 se describen brevemente las características del corpus utilizado, creado ad hoc para el trabajo a partir de materiales de otros corpus preexistentes. En el apartado 3 se exponen y ejemplifican con materiales del corpus las principales diferencias en las técnicas de entrevista tradicionales y las que buscan un modelo más libre y desestructurado. Por último, en el apartado 4, se presenta la metodología de análisis del corpus y los rasgos que van a ser analizados, así como los resultados obtenidos de aplicar el análisis en las distintas muestras.

\section{Algunas notas sobre el corpus empleado}

El corpus empleado para el estudio está formado por cuatro muestras orales correspondientes a situaciones diferentes.

En primer lugar, se recopilaron muestras tomadas de las tres situaciones que ocupan el centro de este estudio: la conversación cotidiana entre iguales, la entrevista dirigida o estructurada, y un tipo de entrevista en el que se han desplegado distintas estrategias para tratar de relajar y desestructurar el encuentro, lo que se denominará entrevista libre o desestructurada.

En segundo lugar, y para tener como referencia en la comparación un registro oral prototípicamente formal, se seleccionaron también materiales de una situación totalmente diferente: la del discurso público de tipo político y académico. Entre las características de este género están su carácter planeado, su estructura monológica y su temática especializada. La audiencia a la que va dirigido no tiene relación necesaria con el emisor y el contexto en que se desarrolla es institucional o académico. Tiene unos objetivos específicos, entre los que destacan transmitir información y conocimiento, de modo que los oradores deben trabar razones y premisas que permitan extraer conclusiones de forma congruente y convincente.

Todas estas características se diferencian claramente de las de la conversación, una interacción espontánea, de temática cotidiana, interactiva, simétrica, que tiene lugar entre hablantes con una fuerte vinculación afectiva y un 
alto grado de conocimiento y vivencias compartidas, y cuyo objeto principal es mantener relaciones sociales.

En algún lugar, más o menos cercano a uno u otro extremo, estarían los dos tipos de entrevista en liza: la entrevista dirigida, tradicional, organizada en torno a un esquema de preguntas y respuestas, y la entrevista libre, a la que se han aplicado estrategias de desformalización y desestructuración para tratar de acercarla a la conversación (ver apartado 3 de este trabajo).

A la hora de seleccionar los materiales para el corpus, se trató de que las cuatro partes que lo conforman fuesen lo más homogéneas posible en todos los aspectos no relacionados con el contexto de situación, que es el factor variable. De este modo, se eligieron materiales similares en lo que respecta al número de palabras, el periodo temporal de recogida y las características socioculturales de los hablantes.

Cada una de las partes tiene aproximadamente 35000 palabras, lo que da un total de 144917. Se trata de un corpus (o más bien un pre-corpus, en el sentido en el que emplea el término Parodi 2010) relativamente pequeño pero suficiente para proporcionar resultados orientativos, y que tiene la ventaja de resultar manejable para el tipo de análisis que se deseaba efectuar.

Todos los materiales fueron grabados en un espacio de tiempo de once años, entre 2003 y 2014, y todos los participantes en las grabaciones son hablantes de español peninsular, con un rango de edad de entre 21 y 45 años $^{2}$, y estudios universitarios. Aunque no hay exactamente el mismo número de hombres y mujeres en cada parte, sí hay un número total equilibrado de hablantes de ambos géneros.

Partiendo de la búsqueda de una cierta homogeneidad en cuanto a las características socioculturales de los hablantes, se tomó el nivel de estudios como referencia. La elección de informantes con estudios superiores responde a dos razones fundamentales.

Por un lado, existe una mayor cantidad y variedad de materiales de este tipo de hablantes. Algunos corpus de entrevistas seleccionan únicamente informantes con estudios universitarios (el Corpus de habla culta de Salamanca, CHCS, por ejemplo). Además, los hablantes con un nivel sociocultural más alto suelen tener un mayor acceso a contextos prototípicamente formales como el político y

\footnotetext{
${ }^{2}$ En la conversación C_SCOM_C_11 hay una brevísima intervención de una hablante de edad no especificada. Dado que su intervención se limita a un saludo y un escueto intercambio cortés, su presencia no se tuvo en cuenta a la hora de describir en conjunto las características socioculturales de los participantes en el corpus.
} 
académico, y por tanto resulta mucho más fácil encontrar muestras tomadas de esos contextos para hablantes con dichas características.

Por otra parte, como señala Simon Vandenbergen (1986), la conciencia de registro se adquiere en parte espontáneamente y en parte mediante la educación formal, de lo que se extrae que los hablantes con un grado más alto de formación académica pueden ser más sensibles lingüísticamente al cambio de situación.

Con todas estas precauciones se trató de reducir la posibilidad de que ciertos fenómenos de variación entre las distintas muestras se pudiesen explicar más por las características de los hablantes que por la situación en la que se encuentran. Queda, sin embargo, un resquicio para la variación, que se encuentra en el origen geográfico específico de los informantes, que son, como se verá, naturales de distintos lugares dentro de España. Esto se explica porque resulta prácticamente imposible encontrar materiales de tan diversa naturaleza recogidos en un área reducida sin variación dialectal. Se tendrá en cuenta, pues, esta circunstancia a la hora de interpretar los resultados. Cabe señalar, de todos modos, que no se ha encontrado documentación relativa a diferencias cuantitativas relevantes en el empleo del tipo de léxico que se va a analizar a continuación entre hablantes de diferentes partes de España ${ }^{3}$.

Con respecto a los dos corpus de entrevistas, se trató de que las diferencias fundamentales atañesen únicamente a la metodología empleada por los entrevistadores en cada caso. Para ello, se intentó lograr cierta homogeneidad en las condiciones sociolingüísticas e interpersonales en que se desarrollaron las interacciones de uno y otro tipo.

Así pues, en todas las entrevistas, tanto tradicionales como libres, las entrevistadoras son mujeres. Los entrevistados, son, en ambos casos, mujeres y hombres.

La media de la diferencia de edad entre entrevistador y entrevistado es muy similar en ambos corpus: 9 años en el caso de la entrevista libre y 8,12 en el de la rígida, en ambos casos a favor del entrevistador.

Por último, aunque en general no existe una relación previa entre entrevistador y entrevistado, en ambos corpus hay alguna entrevista en la que los participantes se conocen previamente.

\footnotetext{
${ }^{3}$ Bernal Linnersand (2007: 78) efectuó un estudio sobre descortesía basado en encuestas que parece sugerir la existencia de una ligera tendencia de los hablantes andaluces a emplear expresiones malsonantes en un abanico de situaciones más amplio que los hablantes de otros lugares de España. Sin embargo, la propia autora admite que el trabajo se basa en una muestra tan reducida que no permite extraer conclusiones generales ni definitivas en ese sentido.
} 
Por supuesto, todo esto no elimina por completo la posibilidad de que ciertas características objeto de análisis en los materiales se puedan explicar por razones distintas a la variación situacional, pero sí se reduce en la medida de lo posible.

En la Tabla 1 se sintetizan las características fundamentales de cada una de las muestras:

Tabla 1. Características de las muestras

\begin{tabular}{|c|c|c|c|c|}
\hline & $\begin{array}{l}\text { Discurso } \\
\text { público }\end{array}$ & $\begin{array}{l}\text { Entrevista } \\
\text { dirigida }\end{array}$ & Entrevista libre & Conversación \\
\hline Origen & $\begin{array}{l}\text { Corpus MAVIR }^{4} \\
\text { Web Congreso de } \\
\text { los Diputados } \\
\end{array}$ & $\begin{array}{l}\text { Proyecto } \\
\text { ESCEGRA }^{6} \\
\mathrm{CHCS}^{7}\end{array}$ & $\begin{array}{l}\text { Corpus } \\
\text { ESLORA }^{8}\end{array}$ & $\begin{array}{l}\text { Corpus } \\
\text { ESLORA }^{9}\end{array}$ \\
\hline $\begin{array}{l}\text { Número de } \\
\text { palabras }\end{array}$ & 35898 & 36780 & 36717 & 35522 \\
\hline $\begin{array}{l}\text { Rango de } \\
\text { edad de los } \\
\text { hablantes }\end{array}$ & 25-41 años & 21-45 años & 21-40 años & 21-35 años \\
\hline $\begin{array}{l}\text { Período de } \\
\text { recogida }\end{array}$ & $2003-2014$ & 2003 у 2005 & 2007 & 2013-2014 \\
\hline
\end{tabular}

\footnotetext{
${ }^{4}$ Corpus formado por presentaciones, conferencias y charlas académicas especializadas de tipo científico técnico, http://cartago.lllf.uam.es/mavir/index.pl.

5 Dado que las transcripciones de la página web no fueron efectuadas con propósitos lingüísticos, aparecen adaptadas a las convenciones de la escritura y depuradas de ciertos fenómenos típicos de la oralidad: repeticiones, reinicios, lapsus, hipérbatos, muletillas... Por este motivo, para ser empleadas en este trabajo, fueron revisadas una a una tomando como referencia el audio y el vídeo, disponibles en la misma web, con el objetivo de restablecer todos los fenómenos que habían sido eliminados o modificados.

${ }^{6}$ Desarrollado en la Universidad de Granada.

${ }^{7}$ Corpus de habla culta de Salamanca.

${ }^{8}$ Desarrollado en la Universidad de Santiago de Compostela (http://eslora.usc.es/) el corpus ESLORA está compuesto por una parte de entrevistas y otra de conversaciones, de manera que fue empleado para obtener muestras de ambos tipos.

${ }^{9}$ Los materiales conversacionales del corpus ESLORA fueron obtenidos mediante grabaciones "secretas": efectuadas sin el conocimiento explícito de los participantes en el momento exacto de la grabación, pero partiendo de su permiso previo por escrito para ser grabados en cualquier momento. Además, todos los participantes firmaron posteriormente un consentimiento para que los materiales fueran empleados en investigación.
} 
A partir de este momento se presentarán ejemplos tomados de las distintas muestras, que se identificarán con un nombre que consta de una o dos iniciales que indican la parte del corpus al que pertenece el ejemplo ( $\mathrm{D}$ para discurso público, ED para entrevista dirigida, EL para entrevista libre y C para conversación), unidas a la denominación de los archivos en sus corpus de origen, o al apellido del autor cuando se trata de un discurso parlamentario. En el caso de los archivos del corpus MAVIR, que tienen nombres de considerable longitud, se han tomado formas abreviadas. A modo de resumen, los nombres de los archivos que conforman el corpus y la muestra a la que pertenecen figuran en la Tabla 2:

Tabla 2. Composición de las muestras

\begin{tabular}{|c|c|c|c|}
\hline Discurso público & Entrevista dirigida & Entrevista libre & Conversación \\
\hline D_Cangrejos & ED_ESCEGRA 2 & EL_SCOM_H13_014 & C_SCOM_C_03 \\
\hline D_Premio & ED_ESCEGRA 3 & EL_SCOM_M13_010 & C_SCOM_C_05 \\
\hline D_Aplicaciones & ED_ESCEGRA 5 & EL_SCOM_M13_012 & C_SCOM_C_06 \\
\hline D_Simancas & ED_ESCEGRA 12 & & C_SCOM_C_16 \\
\hline D_Sáenz & ED_CHCS 1 & & C_SCOM_C_18 \\
\hline Santamaría & ED_CHCS 2 & & C_SCOM_C_19 \\
\hline D_Hernández & ED_CHCS 3 & & C_SCOM_C_11 \\
\hline Gutiérrez & ED_CHCS 4 & & \\
\hline \multicolumn{4}{|l|}{ D_ Ноyо } \\
\hline \multicolumn{4}{|l|}{ D_Garzón } \\
\hline \multicolumn{4}{|l|}{ D_González } \\
\hline \multicolumn{4}{|l|}{ Veracruz } \\
\hline \multicolumn{4}{|l|}{ D_Alegría } \\
\hline D_Alberto Pérez & & & \\
\hline
\end{tabular}

\section{Entrevista dirigida y entrevista libre}

Puesto que uno de los objetivos fundamentales del trabajo es tratar de determinar si las distintas metodologías de entrevista dan como resultado diferencias significativas en el registro de los materiales obtenidos, es oportuno dedicar unas líneas a describir en qué consisten dichas diferencias.

El punto de partida teórico de la entrevista libre, tal y como se entiende en este trabajo, se encuentra en la sociolingüística interaccional de Gumperz y su teoría de la contextualización (Gumperz 1982, 1992). La idea fundamental consiste en que es el discurso de los hablantes el que construye el contexto, de manera que, en el caso de la entrevista libre, la acción comunicativa de los 
entrevistadores tiene como objetivo ir creando una situación interaccional distinta a la de las entrevistas dirigidas, más cercana, informal y flexible, que pretende hacer que los informantes, aun en caso de que tuvieran una concepción previa de lo que iba a ser el evento, acaben por descartarla y adaptarse al nuevo marco.

En este apartado se exponen brevemente algunas de las estrategias fundamentales que los entrevistadores usan en la entrevista libre, en contraste con las empleadas en la dirigida, tomando para ello ejemplos del corpus, de manera que a un tiempo se ilustrarán los conceptos y se expondrán los motivos de la inclusión de cada entrevista en una u otra muestra.

\subsection{Empleo de guion}

En las entrevistas dirigidas el entrevistador estructura la interacción a partir de un guion previo que, con ciertas variantes, aplica a todos los informantes, y del que suele salirse pocas veces, incluso aunque surja algún tema de evidente interés para el entrevistado. De esta manera, la entrevista se desarrolla a partir de la formulación de preguntas estándar (infancia, estudios, tiempo libre, vacaciones), sin relación necesaria entre sí, ni tampoco con las características o gustos del informante.

La entrevista libre, por el contrario, aunque pueda partir de una planificación, se va co-construyendo turno a turno, siguiendo el curso de la conversación y los intereses del informante, de manera que las preguntas necesarias para conducir la interacción vienen motivadas por el flujo conversacional. En el corpus seleccionado estas diferencias estructurales se aprecian claramente.

Comenzando por las entrevistas dirigidas, tres de las cuatro entrevistas de ESCEGRA siguen un guion común con ligeras variaciones, en el que se formulan preguntas prácticamente idénticas (¿puedes describir tu casa?, ¿sueles comer en casa? ¿cocinas?, ¿cómo sería tu boda ideal?, ¿qué recuerdos tienes del colegio?, ¿cómo es tu lugar de veraneo?, ¿has hecho algún viaje o piensas hacerlo?), y donde solo caben ligeras variaciones: por ejemplo, en ED_ESCEGRA 2 y ED_ESCEGRA 3 se pregunta por el tiempo libre, y en ED_ESCEGRA 5 por la masificación universitaria. Hacia el final de la entrevista, y probablemente en función del tiempo transcurrido con respecto al tiempo de grabación requerido, pueden solicitarse algunos detalles sobre alguno de los temas ya tratados, con el fin de alargar un poco el intercambio si es necesario.

En ED_ESCEGRA 12 se aprecian algunas diferencias en cuanto a los temas tratados y el orden en que se abordan, pero no en la concepción estructural de la entrevista. Los cambios probablemente vienen motivados por el hecho de que, mientras todas las anteriores habían sido hechas por la misma entrevistadora, en 
la número 12 entra en juego una investigadora diferente, que aplicará su propio guion, aunque siguiendo las mismas directrices básicas.

En las entrevistas del CHCS el panorama es similar. En la introducción al corpus (Fernández Juncal 2005: 5), se afirma que las entrevistas se desarrollan a partir de un cuestionario «abierto», aunque se añade que cuentan con una serie de «preguntas fijas».

Atendiendo a las entrevistas seleccionadas para este trabajo, lo que se aprecia es que todas ellas giran en torno a dos grandes áreas temáticas: la trayectoria académica y profesional del entrevistado, y la ciudad de Salamanca. Esos módulos temáticos se desarrollan, además, casi siempre a partir de las mismas preguntas formuladas de manera similar, y ocupan la mayor parte de la extensión de la entrevista.

En caso de ser necesario para completar el tiempo de grabación, se introducen a continuación módulos más breves, que se repiten también en las distintas entrevistas, aunque no tienen por qué aparecer todos en todas ellas. Se trata de módulos típicos de este tipo de intercambio: infancia, veraneo, tiempo libre, viajes, libros, películas, comparaciones pasado-presente, etc. Pueden introducirse más o menos temas dependiendo del tiempo que el informante emplee en cada uno. Los cambios de módulo no están motivados conversacionalmente sino por la voluntad de seguir un guion y extender el intercambio.

Estructuralmente, las entrevistas no están adaptadas a las características de los informantes, si bien es cierto que la entrevistadora puede formular alguna pregunta específica para interesarse por un aspecto concreto de la vida o gustos del entrevistado a partir de alguna mención de este, o relacionada con sus características.

En síntesis, no se puede decir que ni las entrevistas de ESCEGRA ni las del CHCS sean totalmente rígidas, ya que admiten cierta variación, pero sí que parten de una idea de entrevista dirigida y guionizada, con un esquema común que solamente admite ligeras variaciones, nunca muy apartadas de los temas previstos inicialmente.

En las tres entrevistas de ESLORA, las clasificadas como libres, el panorama es bien diferente. Los temas que se tratan en cada una son muy diversos, y se pasa de uno a otro de manera no lineal: de un tema se va al siguiente, luego se vuelve al anterior, se avanza de nuevo... En todas ellas hay temas recurrentes en los que los hablantes se sienten cómodos y a los que vuelven una y otra vez siempre que lo desean. Además, los pasos de un tema a otro se producen de manera natural casi siempre sin necesitad de preguntas. No hay cambios bruscos motivados por preguntas "de guion". Las entrevistadoras no pretenden seguir un plan preestablecido, y dejan que el intercambio vaya fluyendo libremente, enlazando 
los temas como en un diálogo improvisado. En la entrevista EL_SCOM_H13_012, el propio informante se percata de la deriva temática del intercambio, que ha pasado sin que apenas se den cuenta de versar sobre temas culturales a otros mucho más cotidianos ${ }^{10}$ :

(1) <Informante> hay que llevarlo tal y hay que llevarlo ir cargando con él y bueno / acabas oliendo dos o tres días a lo que no deberías oler / <simultáneo>o le da la sensación</simultáneo>

<Entrevistador><simultáneo>iqué horror! </simultáneo>

$<$ Informante> pero bueno dejemos <simultáneo>el tema $</$ simultáneo $>$

$<$ Entrevistador $>\quad<$ simultáneo $><$ risa $>$ Dios mío $</$ risa $><$ /simultáneo $>$

<Informante> ¿cómo podemos hablar <alargamiento> / empezar a hablar del periodismo / de Carlos Casares de <alargamiento> la lluvia de <simultáneo>Santiago a la $a</$ simultáneo $>$

$<$ Entrevistador><simultáneo>es que siempre se termina igual $/</$ simultáneo $>$

<Informante> iqué mal final! ¿eh? / <risa> iqué mal final! $<$ risa> <simultáneo>a la mierda y nunca mejor dicho $</$ simultáneo $>$

$<$ Entrevistador $><$ simultáneo $>$ si quieres contarme algo más $/</$ simultáneo $>$ (EL_SCOM_H13_012)

El hecho de que la entrevistadora no siga rígidamente un guion previo no quiere decir que carezca de planificación, sino que solamente recurre a ella en los momentos en que la interacción llega a un punto muerto. Además, cuando recurre a preguntas "de guion", las escoge siempre adaptadas al hablante y al momento concreto, relacionándolas con temas ya tratados anteriormente, de modo que la transición es imperceptible para el entrevistado, como se aprecia en el siguiente ejemplo de la entrevista EL_SCOM_M13_010:

\footnotetext{
${ }^{10}$ Las convenciones de transcripción empleadas en los ejemplos se presentan en el Apéndice 1.
} 
(2) $<$ Informante $>$ [..] aquello // era un aparcamiento $<$ fático=E $>$ de tierra / ¿sabes? no era nada y entonces allí que había un dispensario incluso // donde bah / y entonces los niños sí que estaban más en la calle jugaban más en la calle andaban en bici y tal las niñas / no tanto pero <alargamiento> / pero sí que hacíamos también / bajábamos a la calle con la bici y así /

<Entrevistador> habrás notado <alargamiento> los cambios de la ciudad <simultáneo ¿ ¿no?</simultáneo>

<Informante> ff completamente / (EL_SCOM_M13_010)

Como síntesis a este apartado, se puede afirmar que, aunque las entrevistas que se han clasificado como dirigidas no lo sean totalmente (sin duda puede haberlas todavía más estructuradas), sí lo son en comparación con el desarrollo de las clasificadas como libres.

\subsection{El control sobre la interacción}

En las entrevistas dirigidas se establece una relación comunicativa asimétrica en la que el entrevistador mantiene el control total de la interacción: es el único que hace preguntas, quien propone cada tema y quien decide si es momento de cambiar al siguiente o si quiere ahondar un poco más en el presente. Esto explica que en las entrevistas dirigidas del corpus sea muy frecuente encontrar intervenciones como las de (3) a (5):

(3) E: Bueno vamos a hablar ahora de un tema que no $\langle($ :) $\rangle$ <simultáneo $><$ ruido = I = carraspeo $></$ simultáneo $>$ del que no hay que matar// ¿tienes proyecto de boda cómo sería tu boda en tal caso? (ED_ESCEGRA 02)

(4) E: Bien ahora nos vamos a a mover en un tema algo controvertido/ como es el tabaco/ ¿conoces alguna persona cercana que tenga $\langle(:)>/$ un determinado comportamiento $\langle(:)\rangle$ debido a que fuma? ¿puedes describirlas? (ED_ESCEGRA 02)

E: $\quad$ Bueno y siguiendo $\langle(:)>$ con el tema de la comida/ ¿qué puedes decir de la matanza? ¿eres experto $\langle(:)\rangle$ ? <simultáneo $>\mathrm{I}=\langle(\mathrm{m}:)\rangle\langle/$ simultáneo $\rangle$ ¿has visto la matanza? (ED_ESCEGRA 2) 
Este tipo de intervenciones apenas se da en las entrevistas libres, en las que las entrevistadoras siempre buscan el consenso y la complicidad del entrevistado a la hora de conducir la interacción. Prueba de ello es que en las entrevistas libres se encuentran fragmentos en los que la entrevistadora anima al informante a hablar del tema que le apetezca sin preocuparse de cumplir guion alguno ni del tiempo que quiera explayarse:

(6) <Entrevistador> pero tienes ya muchas cosas para contar / muchas muchísimas //

$<$ Informante> pff y encima hablo como un <risa $>$ hablo por los codos $\langle/$ risa $>$

$<$ Entrevistador> pero eso mola / yo también hablo mucho /

<Informante> ¿sí? /

<Entrevistador> así que no te preocupes // ¿me quieres contar algo más? //

<Informante> pues no sé por poder contarte te podría contar muchísimas cosas // pero también dime tú un poco igual qué es lo que te //

<Entrevistador> no sé / (EL_SCOM_H13_014)

(7) <Entrevistador> si quieres contarme algo más / adelante

/ si no por mí empezamos con el <simultáneo>cuestionario</simultáneo>

<Informante> <simultáneo>yo puedo

estar $</$ simultáneo $>$

<Informante> hablándote horas y horas diciendo chorradas o sea que empezamos ya con el

$<$ Entrevistador $>$ pero te vas a resecar en algún momento y el agua ya tiene $\langle\mathrm{gl}\rangle$ babuxas $\langle/ \mathrm{gl}\rangle\langle$ risa $\rangle$ entonces $</$ risa $>$

<Informante> pues entonces ya empezamos con el cuestionario

$<$ Entrevistador> ¿sí?

<Informante> sí sí sí (EL_SCOM_H13_012) 
La manera de finalizar el intercambio que se observa en (7) contrasta con la de las entrevistas dirigidas, que en muchos casos terminan con un escueto gracias o muchas gracias después de la respuesta a la última pregunta, y en otros simplemente informan al entrevistado de que han terminado, sin darle opción a añadir nada más:

$$
\begin{aligned}
& \text { <Entrevistador> sí // <fático } \mathrm{hb}=\text { " } 001 " />/ / \text { bueno // } \\
& \text { <ruido desc="chasquido de boca"/> eeh pues ya hemos } \\
& \text { terminado esta parte (ED_CHCS) }
\end{aligned}
$$

Por otra parte, mientras que en las entrevistas dirigidas los informantes se limitan a hablar de lo que les indica el entrevistador, en las libres son ellos quienes muchas veces introducen temas de manera espontánea.

Por ejemplo, el de las leyes antitabaco es un tema recurrente en las entrevistas de ESLORA, normalmente sacado a colación por las entrevistadoras por ser un asunto de actualidad (en aquel momento) que interesaba a casi todos los hablantes y que, situándolos a favor o en contra, solía motivar animadas secuencias argumentativas. Sin embargo, en el caso que se presenta a continuación, a partir de algunos comentarios sobre fumadores y no fumadores, es el propio informante el que introduce el tema de las leyes:

(9) <Informante> es // y bueno y luego están las leyes estas del tabaco / ya <alargamiento> dando opiniones así que / que no son ni una cosa ni la otra / vamos que son <alargamiento> / maquillaje en plan // para fastidiar a los fumadores / pero no arreglando nada / es decir ¿a mí qué <alargamiento> demonios me importa que tenga que ir a un bar a comprar tabaco? <silencio> y que alguien / esté el camarero con <alargamiento> cara de asco haciendo esto / plic / (EL_SCOM_H13_012)

En ocasiones lo que sucede es que los informantes, sin que el entrevistador diga nada, vuelven al hilo temático cuando se desvían:

(10) <Informante> volviendo ahí que estamos yéndonos por los cerros de Úbeda / (EL_SCOM_H13_012) 
La libertad interaccional que sienten los entrevistados llega al punto de que pueden ser ellos mismos los que, justo al contrario de lo que se veía en (3)-(5), den por zanjado un tema:

(11) <Informante> hay que llevarlo tal y hay que llevarlo ir cargando con él y bueno / acabas oliendo dos o tres días a lo que no deberías oler / <simultáneo>o le da la sensación $</$ simultáneo $>$

<Entrevistador>
horror!</simultáneo>

A veces incluso puede llegar a haber un intercambio de roles, en el que es el informante el que formula preguntas a la entrevistadora:

(12) <Entrevistador> hm hm hm hm hm <silencio> sí / sí $<$ ininteligible> bueno / yo acabo de dejar de comerme las uñas pero <alargamiento> / <simultáneo>era mi gran vicio <alargamiento> pero <alargamiento> vamos $</$ simultáneo $>$

$<$ Informante> <simultáneo >creo creo que creo que es un $</$ simultáneo $>$ vicio / <risa $>$ eso no </risa $>$ / los vicios no todos los vicios dan dinero $¿$ eh? / porque ese

<Entrevistador > <simultáneo>no este no</simultáneo>

$<$ Informante $><$ simultáneo $>$ no $/</$ simultáneo $>$ no tiene beneficio ninguno $<$ risas $=$ I $>$ realmente $</$ risa $>$ /

$<$ Entrevistador $><$ risa $>$ solo me machacaba a mí misma $</$ risa $><$ simultáneo $><$ risa $>$ pero bueno </risa $\| /</$ simultáneo $>$

<Informante> <simultáneo>pero / ¿a que quitaba también la ansiedad? $</$ simultáneo> (EL_SCOM_H13_012) 


\subsection{Comportamiento interaccional del entrevistador e implicación personal}

En las entrevistas dirigidas el entrevistador actúa, a grandes rasgos, como mero transmisor del guion previamente diseñado. Conversacionalmente, esto se refleja en que se limita a preguntar y, en ocasiones, a emitir marcadores de recepción (Vázquez Veiga 2003). Sus intervenciones son casi siempre de tipo iniciativo, mientras que las del informante son de tipo reactivo, lo que da como resultado una estructura uniforme en pares adyacentes de pregunta-respuesta.

El hecho de que el entrevistador se limite a ese tipo de intervenciones determina que adquiera un rol totalmente despersonalizado: no transmite sentimientos, ni expresa opiniones, ni expone datos o anécdotas biográficas que lo puedan "personalizar" ante al informante, para el que es simplemente un investigador realizando su trabajo.

Este comportamiento por parte del entrevistador, defendido por autores como López Morales (1994: 77), Vázquez Veiga (2003: 24) o Pitkowski (2010: 108-9), presenta algunas ventajas, tanto desde el punto de vista de los materiales obtenidos, más homogéneos y comparables que aquellos recolectados mediante entrevistas libres, como desde la perspectiva del desarrollo de la propia interacción.

En primer lugar, el hecho de que el cometido del entrevistador se reduzca básicamente a transmitir preguntas preparadas previamente, las mismas para un gran número de informantes, reduce de manera considerable el tiempo de preparación necesario para cada entrevista. Por otro lado, las posibilidades de que el intercambio se complique son escasas, ya que las cuestiones suelen ser muy genéricas y adecuadas para cualquier tipo de hablante. Además, al limitar sus intervenciones a las preguntas de guion, el entrevistador minimiza los riesgos de que surja cualquier conflicto comunicativo derivado de comentarios desafortunados, inferencias erróneas, preguntas indiscretas o cualquier otra intervención potencialmente amenazante fruto de la improvisación. Por otro lado, la estructura del intercambio, basada en preguntas y respuestas, se ajusta exactamente a las expectativas del informante acerca del evento de entrevista, lo que contribuye a que este se sienta seguro y sin dudas respecto al rol que debe desempeñar.

La contrapartida se encuentra, sin embargo, en que el comportamiento interaccional del entrevistador es radicalmente distinto al de un participante en una conversación coloquial, lo cual contribuye inevitablemente a formalizar el encuentro y, por tanto, a acentuar la paradoja del observador. 
En los dos corpus de los cuales se seleccionaron las entrevistas dirigidas para este trabajo, la voluntad deliberada de "despersonalizar" el rol de los entrevistadores queda clara desde un principio. En el prólogo del CHCS (Fernández Juncal 2005: 5) se especifica que la función del entrevistador se limita a «provocar el monólogo». En el caso de ESCEGRA, en la introducción a los materiales del nivel de estudios medios, se apunta como una de las mayores virtudes de la entrevistadora principal (que participa en una de las entrevistas seleccionadas para el corpus), la «inhibición de la propia personalidad en beneficio del valor de la muestra» (Moya Corral 2008: 23). Los materiales de uno y otro corpus son claro reflejo de la perspectiva metodológica adoptada.

En las muestras del CHCS las intervenciones de la entrevistadora son, mayoritariamente, de dos tipos: preguntas o secuencias con valor interrogativo, y marcadores de recepción. Solo con un análisis detenido se pueden encontrar, en algunas entrevistas, intervenciones que se salen de esta norma, como por ejemplo turnos colaborativos:

(13) <Informante> [...] en Salamanca mmm los organismos eeh son pues como compartimentos estancos por así decir son eeh núcleos muy cerrados // <fático $\mathrm{hb}=$ "001"/> eemm es muy difícil que salgan plazas las pocas plazas que salen están entre comillas politizadas y es muy difícil hacerse un hueco // no es imposible porque yo he entrado y he entrado por una vía normal con lo cual te das cuenta que

<Entrevistador> $>$ es
posible</simultáneo>
<Informante><simultáneo ><ruido desc="chasquido de
boca"/> posibilidades </simultáneo> hay que no es
imposible // pero realmente es difícil // (ED_CHCS 1)

Sin embargo, este tipo de intervenciones son muy minoritarias con respecto a las preguntas y los marcadores de recepción.

En ESCEGRA, la situación es similar, con la única diferencia de que la organización en pares adyacentes de pregunta-respuesta es todavía más estricta, y la actitud poco implicada de las entrevistadoras, más constante. La práctica totalidad de las intervenciones de las entrevistadoras se corresponde con preguntas. No hay, siquiera, marcadores de recepción que constituyan turnos independientes, solamente algunos situados inmediatamente antes de la 
formulación de una pregunta. En ningún caso se interrumpe al hablante, ni siquiera con turnos colaborativos. Simplemente se formula una pregunta, se deja que el informante termine su parlamento $\mathrm{y}$, a continuación, se formula la siguiente.

En las cuatro entrevistas seleccionadas de ESCEGRA las únicas intervenciones sin valor interrogativo que se localizaron se corresponden, bien con alguna aclaración o apunte sobre la pregunta formulada, bien con intervenciones de cierre situadas al final del intercambio, para dar las gracias al informante o para indicarle que la entrevista ha terminado.

La figura del entrevistador en las entrevistas libres es radicalmente distinta, ya que muestra un comportamiento interaccional que se acerca mucho más al de cualquier conversador. En las entrevistas seleccionadas para el corpus, las entrevistadoras formulan preguntas, pero muchas menos que sus homólogas de las entrevistas dirigidas. Además, las cuestiones tienen forma diferente. Mientras que en las entrevistas dirigidas las preguntas tipo adquieren la forma de enunciados completos con valor independiente del contexto ( $Y Y$ cómo es tu casa aquí en Granada?), en la entrevista libre la mayoría son muy breves, una, dos o tres palabras, muchas veces sin valor léxico. Son totalmente dependientes del contexto, ya que parten de las intervenciones del informante y piden más detalles, causas o explicaciones sobre algún aspecto introducido en ellas, empleando para ello todo tipo de elementos deícticos, o repitiendo algún elemento de la intervención precedente:

(14) <Informante> que lo conocí <alargamiento> / cuando yo volví de Inglaterra estaba por aquí // y <alargamiento> estaba trabajando aquí en una en una productora un poco horrible bastante cutre <silencio> ff que me da solo escalofrío recordarle <risa/> casi acabo a puñetazos con uno / <énfasis> casi no </énfasis> / acabé ca $<$ palabra_cortada> a puñetazos con el jefe pero bueno /

<Entrevistador> <simultáneo> ¿por? <risa> ¿por qué? $</$ risa $></$ simultáneo $>$

$<$ Informante > <simultáneo $>$ eh porque $</$ simultáneo $>$ (EL_SCOM_H13_014)

(15) <Informante> se murió $\mathrm{hm} /$ <ruido=chasquido boca> pero bueno / nada un señor así muy <alargamiento> tenía párkinson ya de aquella <simultáneo>iba ahí</simultáneo> 


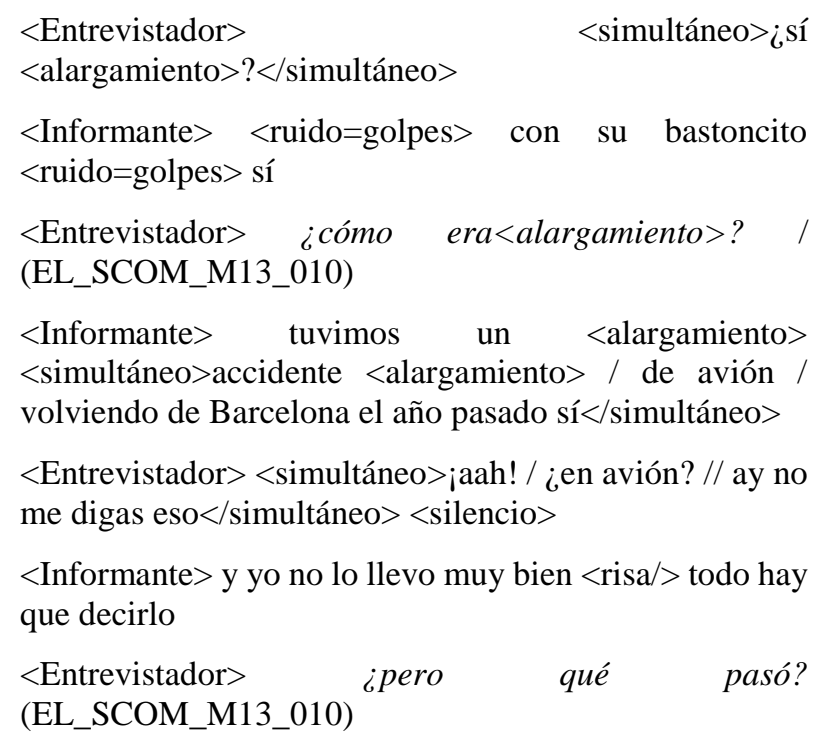

Según Biber et al. (1999: 1046), este tipo de preguntas breves son muy frecuentes en la conversación. Trabajando sobre materiales de inglés conversacional, estos autores se encuentran con que casi la mitad de las preguntas del corpus están formadas por expresiones simples como Really? o And what for?, similares a las de (14)-(16). Para los autores, las preguntas de este estilo tienen una función cohesiva ya que dependen de la información compartida anteriormente por los interlocutores.

En efecto, esta diferencia en el tipo de preguntas, y en general en el modo de conducir la interacción las entrevistadoras, motiva que las entrevistas libres estén mucho más cohesionadas que las rígidas, que son mucho más fragmentarias, ya que están conformadas por pares de pregunta-respuesta prácticamente independientes. Prueba de ello es que en muchos casos se podrían desordenar y la interacción seguiría siendo igualmente comprensible. En cambio, las entrevistas libres constituyen un todo, ya que las partes están enlazadas, imbricadas, y mantienen una relación de interdependencia.

Por otra parte, las intervenciones que no se corresponden con preguntas no se limitan en las entrevistas libres a marcadores de recepción, sino que son de muy diverso tipo, y con ellas las entrevistadoras muestran su implicación en el intercambio. Sus personalidades, gustos, biografía, quedan al descubierto, humanizándolas ante los informantes, de manera que ya no se presentan únicamente como profesionales llevando a cabo una investigación, sino como 
conversadoras que expresan opiniones (en ocasiones contrarias a las del informante), introducen referencias a su vida personal, muestran empatía, bromean o emplean la ironía, tal y como se aprecia en los ejemplos Errore. L'origine riferimento non è stata trovata.-(19):

<Informante> y a mí me pasa y es un poquito de calor / que la gente dice <cita $>$ ay / que se agradece $</$ cita $>$ no yo eso / y yo <cita> leches </cita> / <risa/> a mí déjame mi mes de noviembre / con su siete de la tarde de noche / <simultáneo>con su lluvia </simultáneo >

$$
\begin{aligned}
& <\text { Entrevistador }> \\
& \text { verdad? }</ \text { simultáneo }>/ /
\end{aligned}
$$

<Informante> me siento más contento / los días son más cortos <silencio> y <alargamiento> y no hay tanta <alargamiento> / calor y es <alargamiento> $<$ simultáneo>es más fácil</simultáneo $>$

<Entrevistador> <simultáneo>pero ¿para qué quieres </simultáneo> que los días sean más cortos? // a mí me parece <risa> una cosa $<$ simultáneo $>$ terrible $</$ simultáneo $></$ risa $>$

<Informante> <simultáneo>a mí porque<simultáneo> ah / pues las noches son mucho más interesantes / (EL_SCOM_H13_12)

(18) <Informante> eeh / es que el problema de Filología $<$ alargamiento> <risa/> es que <alargamiento> si le das muchas vueltas a las palabras / cuando dices una palabra / dices por ejemplo / proyecto proyecto proyecto proyecto proyecto / la dices tantas veces que llega un momento en que pierden el sentido [...] darles muchas vueltas a las palabras da dolor de cabeza y pierden su significado / o dices esto de monja monja monja <simultáneo>monja monja</simultáneo $>$

\footnotetext{
$<$ Entrevistador $><$ simultáneo>sí sí </simultáneo>

<Informante> y acabas diciendo otro con <palabra_cortada> / otra cosa totalmente diferente / siendo así y reduciendo las cosas al punto / [...] <simultáneo>es / es decir opinión / es decir me imagino que $</$ simultáneo $>$
} 
<Entrevistador > <simultáneo> bueno / a ver / un poquito más complejo ¿no? / <risa> es el asunto pero $<$ alargamiento $></$ risa $></$ simultáneo $>$

$<$ Informante> no estaréis en clase diciendo monja monja $<$ risa/> monja monja <simultáneo>porque si no sí</simultáneo>

<Entrevistador> <simultáneo>no / solamente en primero</simultáneo> después ya pasamos a otras $<$ risa/> palabras (EL_SCOM_H13_12)

(19) LInformante $>$ [...] o sea los gatos ¿sabes? no <alargamiento> no son / yo por lo menos los que conozco de otras personas / no dejan que los tengas así y esta bueno / la cogía la apretaba así que y le salía todo el aire y después le pff / le soplaba por la nariz <risa/> como para inflarla otra vez / le hacía mil perrerías <risa> la verdad </risa> pero / se dejaba /

$<$ Entrevistador> ¿será la raza esta <simultáneo>siamesa? $</$ simultáneo $>$

<Informante> <simultáneo>yo no lo sé</simultáneo> supongo es que <alargamiento> por eso yo estoy dudando pero $\sim$ Emilio quiere $<$ simultáneo $>$ el ruso este $<$ risa/ $></$ simultáneo $>$

<Entrevistador> es que en mi casa mis padres tuvieron un siamés que la mató la perra <fático=I> porque le fue a comer <simultáneo>al <alargamiento> sitio </simultáneo >

<Informante> <simultáneo>la comida</simultáneo>

$<$ Entrevistador> de la perra <fático=I> y la / le mordió la cogió con la boca / la lanzó / y la mató // y era así también <alargamiento>

<simultáneo >cariñosa </simultáneo >

(EL_SCOM_M13_010)

Otro aspecto destacable que puede observarse, por ejemplo, en (17), consiste en que las entrevistadoras no siempre esperan a que los informantes terminen sus turnos para intervenir, sino que en ocasiones se solapan con ellos. En algunos casos se trata simplemente de intervenciones colaborativas o marcadores de recepción que no disputan el turno al informante, pero en otros, como sucede en 
la segunda intervención de la entrevistadora en (17), se interrumpe al informante, arrebatándole el turno e impidiendo que complete su intervención.

Tradicionalmente, la interrupción por parte del entrevistador, incluso la de tipo colaborativo, está altamente desaconsejada en la entrevista sociolingüística. Así se refleja, por ejemplo, en el documento metodológico de PRESEEA (PRESEEA 2003: 15), en donde se recalca que «los investigadores [...] procurarán interrumpir a los hablantes lo menos posible». Pitkowski (2010: 108), por su parte, señala que la función del entrevistador es «Permitir que el informante hable, sin interrumpirlo».

Sin embargo, en las entrevistas seleccionadas no se documentaron casos en los que interrupciones como la que se acaba de mostrar provocasen ningún tipo de conflicto en la interacción que pusiese en peligro o dificultase su desarrollo. Más allá de esto, los datos analizados muestran que en casos como el de (17), las interrupciones forman parte de un comportamiento interaccional del entrevistador que contribuye a desestructurar el encuentro y que puede dar lugar a secuencias cercanas a la conversación informal. En (17), la entrevistadora interrumpe al informante para cuestionar su afirmación vehementemente (pero ¿para qué quieres que los días sean más cortos?a mí me parece una cosa terrible), implicándose para ello de manera personal, dejando al descubierto sus gustos y parte de su personalidad. Tanto el contenido personal de la intervención como el hecho de que interrumpa el turno del informante para cuestionarlo (algo también desaconsejado por algunos autores, como Vázquez Veiga 2003), contribuyen, por un lado, a humanizar el intercambio, y por otro a flexibilizar su estructura. Al mismo tiempo, la entrevistadora está obligando al informante a implicarse también personalmente en la interacción defendiendo su punto de vista. Los roles de entrevistador y entrevistado, investigador e informante, se van desdibujando y dejan paso a dos hablantes defendiendo sus respectivas posturas.

Todas estas circunstancias tienen su reflejo en la estructura general de la interacción. La organización casi perfecta en pares adyacentes de preguntarespuesta que se veía en las entrevistas dirigidas se diluye en las libres, dando lugar a estructuras mucho más complejas.

Con el objetivo de ilustrar de manera cuantitativa esta afirmación, se ha elaborado una tabla comparativa en la que se han clasificado las intervenciones de las entrevistadoras en todas las entrevistas del corpus, dirigidas y libres. Para que la presentación resulte clara, se distingue únicamente entre tres tipos de intervenciones: en primer lugar, aquellas que contienen actos directivos en forma de preguntas o imperativos con verbos de habla (dime, cuéntame), y en segundo, las intervenciones formadas únicamente por marcadores de recepción. Estos dos tipos serían los propios de una estructura de entrevista tradicional. En tercer lugar, 
se situaron en otro grupo todas aquellas intervenciones que no entran en ninguno de los dos supuestos anteriores y que, por tanto, constituirían una ruptura de la estructura de pregunta-respuesta. Entrarían dentro de esta clase intervenciones que contienen opiniones, bromas, aclaraciones, y comentarios de todo tipo. Se dejó un espacio también para aquellas intervenciones que por estar truncadas o por ser ininteligibles resultan imposibles de clasificar.

Los resultados de la clasificación se muestran en la Tabla 3:

Tabla 3. Tipos de intervenciones de las entrevistadoras en la entrevista dirigida y la entrevista libre

\begin{tabular}{|c|c|c|c|c|c|c|c|c|}
\hline \multirow[b]{2}{*}{$\begin{array}{l}\text { Entrevista } \\
\text { dirigida }\end{array}$} & \multicolumn{2}{|c|}{$\begin{array}{l}\text { Actos } \\
\text { directivos }\end{array}$} & \multicolumn{2}{|c|}{$\begin{array}{l}\text { Marcadores de } \\
\text { recepción }\end{array}$} & \multicolumn{2}{|c|}{$\begin{array}{l}\text { Truncadas o } \\
\text { ininteligibles }\end{array}$} & \multicolumn{2}{|l|}{ Otros } \\
\hline & $\%$ & $\mathbf{n}$ & $\%$ & n & $\%$ & $\mathbf{n}$ & $\%$ & $\mathbf{n}$ \\
\hline ESCEGRA_02 & $98 \%$ & 49 & 0 & 0 & 0 & 0 & $2 \%$ & 1 \\
\hline ESCEGRA_03 & $92,86 \%$ & 26 & 0 & 0 & 0 & 0 & $7,14 \%$ & 2 \\
\hline ESCEGRA_05 & 91,66 & 22 & 0 & 0 & 0 & 0 & $8,33 \%$ & 2 \\
\hline ESCEGRA_12 & $95 \%$ & 19 & 0 & 0 & 0 & 0 & $5 \%$ & 1 \\
\hline CHCS_1 & $32,18 \%$ & 28 & $54,02 \%$ & 47 & $1,15 \%$ & 1 & $12,64 \%$ & 11 \\
\hline CHCS_2 & $60 \%$ & 18 & $26,67 \%$ & 8 & 0 & 0 & $13,33 \%$ & 4 \\
\hline CHCS_3 & $72,92 \%$ & 105 & $14,58 \%$ & 21 & $4,17 \%$ & 6 & $8,33 \%$ & 12 \\
\hline $\mathrm{CHCS}_{-} 4$ & $69,12 \%$ & 47 & $23,53 \%$ & 16 & $2,94 \%$ & 2 & $4,41 \%$ & 3 \\
\hline TOTAL & $69,62 \%$ & 314 & $20,4 \%$ & 92 & $1,99 \%$ & 9 & $7,98 \%$ & 36 \\
\hline \multicolumn{9}{|l|}{$\begin{array}{l}\text { Entrevista } \\
\text { libre }\end{array}$} \\
\hline SCOM_H13_014 & $34,19 \%$ & 40 & $9,4 \%$ & 11 & $2,56 \%$ & 3 & $53,85 \%$ & 63 \\
\hline SCOM_H13_012 & $20,29 \%$ & 85 & $29,12 \%$ & 122 & $1,19 \%$ & 5 & $49,4 \%$ & 207 \\
\hline SCOM_M13_010 & $32,5 \%$ & 52 & $16,87 \%$ & 27 & $3,12 \%$ & 5 & $47,5 \%$ & 76 \\
\hline TOTAL & $25,43 \%$ & 177 & $22,99 \%$ & 160 & $1,87 \%$ & 13 & $49,71 \%$ & 346 \\
\hline
\end{tabular}

Los datos de la Tabla 3 muestran con claridad tendencias prácticamente opuestas entre las muestras de entrevista dirigida y las de entrevista libre. En el conjunto de las entrevistas dirigidas, el 69,62\% de las intervenciones de las entrevistadoras se corresponde con preguntas o imperativos con verbos de habla. Si a eso se le suma el 20,4\% que están compuestas únicamente por marcadores de recepción, resulta que un $90,02 \%$ de las intervenciones se engloban dentro de la estructura prototípica de entrevista. Resultan especialmente llamativas las cifras individuales de las entrevistas del corpus ESCEGRA, en las que las intervenciones formadas por preguntas e imperativos se elevan en todos los casos por encima del $90 \%$. 
En las entrevistas libres el panorama es diferente: las intervenciones que contienen actos directivos constituyen únicamente el $25,43 \%$ del total, y las intervenciones con un peso relativo más grande son aquellas que no se corresponden ni con preguntas ni con imperativos ni con marcadores de recepción. Este tipo de intervenciones alcanza casi un $50 \%$ del total.

Otro dato cuantitativo que puede resultar de interés como reflejo de los diferentes comportamientos interactivos de las entrevistadoras en uno y otro tipo de entrevistas es el del porcentaje de habla solapada. Así, en la muestra de entrevista libre, el habla simultánea constituye el 11,42\% del total, con una entrevista, la SCOM_H13_012, en la que asciende hasta el 21,22\%. En la muestra de entrevista dirigida, en cambio, el habla solapada se reduce al 1,7\% del total, incluyendo casos en los que no se registra ningún caso de habla simultánea.

\section{Análisis de corpus: léxico coloquial y léxico malsonante}

Como se apuntó en la introducción, la segunda parte de este trabajo tiene como objetivo determinar si existen diferencias de registro entre los materiales conversacionales y los obtenidos mediante entrevistas, y también si dentro de los materiales tomados de entrevistas existen diferencias en función de la metodología específica empleada en ellas. Concretamente, el objetivo es caracterizar cada una de las muestras con respecto al rasgo de la informalidad discursiva.

A la hora de decidir qué elementos analizar para lograr este objetivo las posibilidades son múltiples, dado que la variación de registro afecta a todos los niveles lingüísticos: fónico, morfosintáctico, discursivo y léxico. De entre todos ellos se decidió centrar el análisis en este último, el plano léxico, un componente que, como señala López Serena (2007: 181), quizá sea aquel con más larga tradición en los estudios de variación hispánicos, hasta el punto de que a finales de los años 80, Narbona (1988 [1989]) se lamentaba de que su excesivo protagonismo relegaba a la marginalidad el estudio de los demás niveles lingüísticos.

La explicación a esta situación puede encontrarse, quizás, en el hecho de que el componente léxico es el aspecto que resulta más evidente para cualquier hablante a la hora de diferenciar la lengua formal de la informal. Así como otros rasgos coloquiales pueden pasar más desapercibidos, cualquier hablante adulto competente sabe perfectamente qué palabras o expresiones jamás emplearía en un contexto formal, ya que resultaría inadecuado o incluso grosero, del mismo modo que otras resultarían impropias en un contexto familiar y relajado. Y en sentido 
contrario sucede lo mismo: los hablantes pueden identificar un contexto como relajado e informal al reconocer el empleo de ciertos elementos léxicos, o también emplear cierto vocabulario para tratar de "crear" un determinado contexto. En este sentido, Quaglio (2009: 109), siguiendo a Cooper (2001), considera que en el componente léxico se encuentran los marcadores más obvios de informalidad lingüística.

Las características del léxico coloquial han sido ampliamente tratadas en la lingüística hispánica. Entre los aspectos más destacados por los autores está su carácter reducido respecto al léxico común (Koch \& Oesterreicher 1990, Briz 1998, 2000, 2002), que implica el empleo repetido de formas con amplia capacidad significativa, incluyendo las palabras ómnibus (Koch \& Oesterreicher 1990, López Serena 2007) o proformas (Briz 2002), y que tiene como consecuencia que el habla coloquial muestre un índice de densidad léxica más bajo que el de otros registros (Domínguez Mujica 2005, López Serena 2007). También se hace referencia en la bibliografía a su carácter abierto a la entrada de neologismos, términos procedentes de léxicos especiales y de argot (Briz 1998, 2002), a su concentración en torno a campos semánticos relacionados con la vida cotidiana (Briz 1998, 2000) o con la afectividad y las emociones (Koch \& Oesterreicher 1990), y a su relación con la metáfora (Briz 1998, 2002; Sanmartín 2000).

Teniendo todo esto en cuenta, se desarrolló un análisis de la frecuencia y distribución de ciertos elementos léxicos como índice de la formalidad o informalidad de las muestras. Se analizó en primer lugar el denominado léxico coloquial, entendiendo como tal aquel que muestra una clara preferencia por aparecer en situaciones de uso informales (Briz 2002). Dentro de este grupo caben términos procedentes del argot o de léxicos especiales, neologismos, metáforas de la vida cotidiana, y términos con una capacidad significativa muy amplia y poco precisa. Se incluyeron también en el estudio los términos y expresiones malsonantes, que Briz $(1998,2000)$ relaciona con la frecuente tendencia a la intensificación de los registros más informales y de los que Bernal Linnersand (2007: 78) dice que son propensos a aparecer en situaciones de «características prototípicamente coloquiales».

\subsection{Metodología}

Léxico coloquial y léxico malsonante se situaron para el análisis en una escala de dos niveles, partiendo de la premisa de que las palabras y expresiones malsonantes constituyen el caso más extremo de léxico informal, en el sentido de que tienen contextos de uso más restringidos que el léxico coloquial general. 
Para la determinación de las unidades objeto de análisis, se evitó hacer solamente búsquedas específicas basadas en la bibliografía, sorteando de este modo el riesgo de estar dejando fuera del análisis casos que, por la razón que fuese (incorporación reciente, localización geográfica reducida) no aparecen en la bibliografía sobre el tema aunque estén efectivamente presentes en los textos. El punto de partida fue, pues, la revisión manual completa del corpus, destinada a localizar todos los posibles casos de este tipo de palabras, y solo en un segundo momento se acudió a las búsquedas automáticas, efectuadas con WordSmith (versión 4.0).

\subsection{Resultados}

\subsubsection{Palabras y locuciones coloquiales}

La determinación de lo que constituye o no léxico coloquial puede resultar conflictiva, dada, como señala Briz (2002), la ausencia de diccionarios de frecuencias del español y de estudios estadísticos que arrojen resultados claros en este sentido. Para tratar de evitar subjetivismos y circularidades, se recurrió a la combinación de distintas fuentes y recursos.

En primer lugar se empleó como guía y referencia estable la consulta del DLE. Sin embargo, no todos los elementos identificados a priori en el corpus como léxico coloquial aparecen en el diccionario académico. Por este motivo se recurrió a diccionarios específicos de lenguaje coloquial como el Diccionario de coloquialismos y términos dialectales del español (Fitch 2011). Además, y debido a que este tipo de palabras constituye un grupo dinámico, con continuas incorporaciones, se consultaron diccionarios y glosarios en línea, más actualizados, como Wordreference, Wiktionary, The Free Dictionary y Qué significado, siempre con la precaución necesaria al manejar recursos, algunos de ellos, que pueden ser modificados por cualquier usuario sin un excesivo control. En todos ellos se empleó como criterio para la inclusión en el estudio la marca coloquial y, en algunos casos, jerga.

En ciertos casos en los que alguna expresión, por la razón que fuese, no se recogía en ninguno de los diccionarios consultados, se recurrió a las páginas coloquialmente.com, definida en su portada como un «Glosario español de estar por casa» y jergasdehablahispana.org, portal dedicado «al lado coloquial, menos formal del español». Si en los diccionarios generales se empleaban las marcas de coloquial o jerga como guía, en el caso de estas páginas, el simple hecho de aparecer en ellas se consideró indicio suficiente para incluir una expresión en el estudio.

Todas estas consultas se efectuaron con el fin fundamental de comprobar si el carácter coloquial de una palabra o expresión alcanzaba un reconocimiento 
general más allá de la intuición personal. Aun así, como ya se apuntó, la distinción formal-informal puede resultar muy resbaladiza si se efectúa de modo apriorístico, y conlleva el riesgo de caer en argumentaciones circulares. Este peligro se sorteó aplicando las búsquedas a los cuatro tipos de muestras, de manera que la verdadera comprobación del carácter formal o informal del grupo de piezas léxicas que se seleccionó lo determinarán las frecuencias en los corpus prototípicos, el prototípicamente formal y el prototípicamente coloquial.

Antes de mostrar los resultados de las búsquedas, cabe hacer algunas puntualizaciones más:

- Este apartado incluye no solamente unidades léxicas simples de todo tipo (sustantivos, adjetivos, verbos), sino también locuciones y expresiones fijadas.

- Dentro de la lista hay tanto términos intrínsecamente coloquiales como chorrada, flipar o molar, como otros que pueden ser coloquiales o estilísticamente neutros dependiendo del contexto y/o el tipo de construcción en que se integren: tío/tía, pasta, rajar etc. Lógicamente, los resultados de las búsquedas de los elementos del segundo tipo se revisaron cuidadosamente para seleccionar y contabilizar solamente aquellos casos en que se emplea la acepción buscada y descartar el resto.

- Se incluyeron también palabras que han sufrido un proceso de acortamiento, pero no cualquier palabra acortada, sino solamente las que tienen marca de coloquial en el DLE, ya que hay términos acortados que están totalmente integrados en la lengua, como foto o corto, que resultarían muy dudosos como marcadores de coloquialidad.

Dicho esto, los resultados de las frecuencias del léxico coloquial se presentan sintetizados en la Tabla 4 y las Figuras 1 y $2^{11}$.

Tabla 4. Frecuencias de léxico coloquial (síntesis)

\begin{tabular}{lllll}
\hline & Discurso & $\begin{array}{l}\text { Entrevista } \\
\text { dirigida }\end{array}$ & $\begin{array}{l}\text { Entrevista } \\
\text { libre }\end{array}$ & Conversación \\
\hline Unidades léxicas simples & 24 & 35 & 212 & 388 \\
Palabras acortadas & 0 & 6 & 21 & 30 \\
Unidades fraseológicas & 4 & 32 & 82 & 50 \\
\hline
\end{tabular}

${ }^{11}$ La lista completa de elementos léxicos coloquiales con sus respectivas frecuencias se encuentra en el Apéndice 2. 


\begin{tabular}{lllll}
\hline TOTAL & 28 & 73 & 315 & 468 \\
RATIO x1000 & 0,78 & 1,98 & 8,58 & 13,17 \\
\hline
\end{tabular}

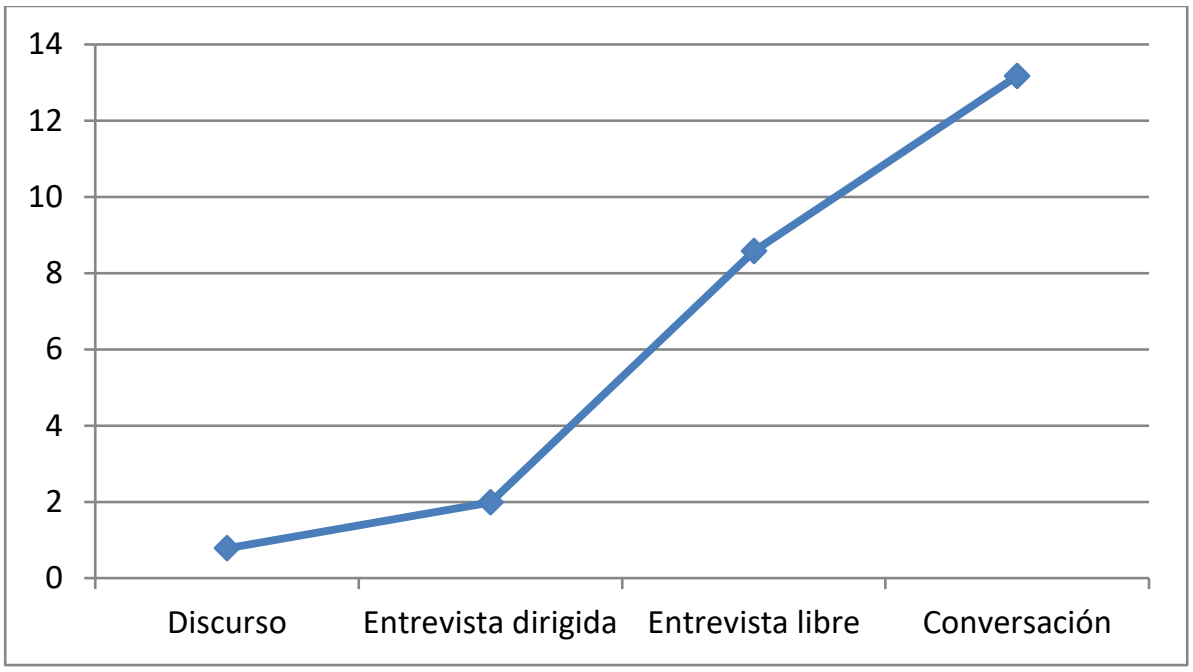

Figura 1. Frecuencias de léxico coloquial (ratio x1000)

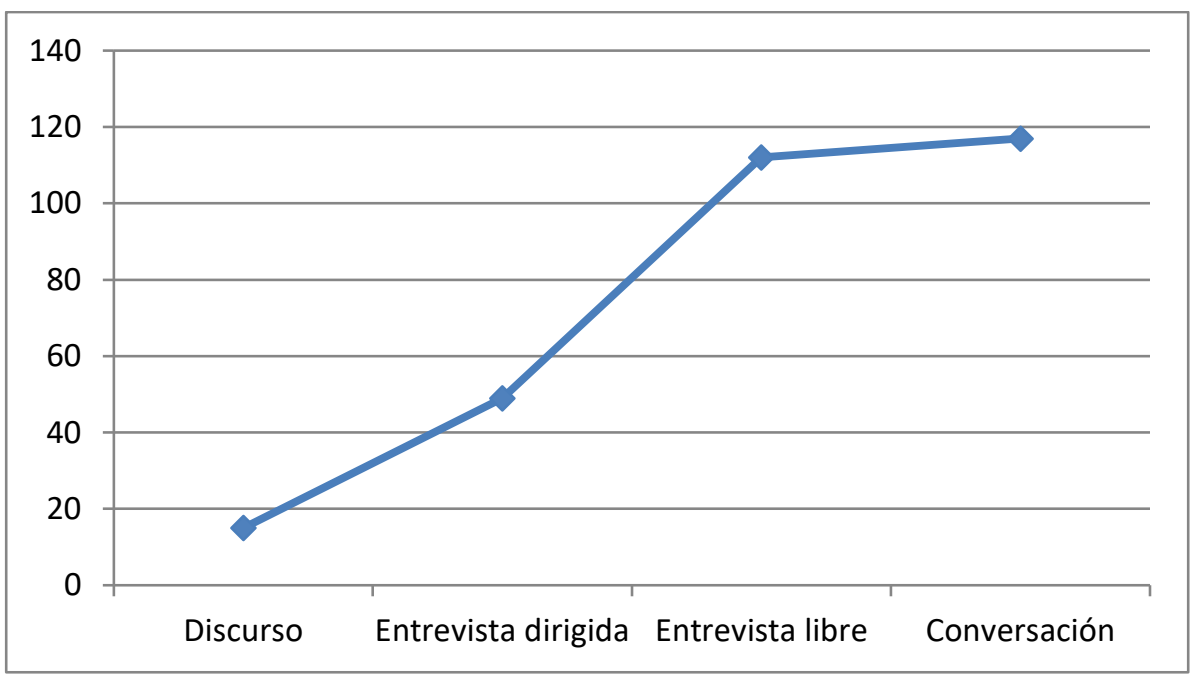

Figura 2. Términos coloquiales diferentes en cada muestra 
Lo primero que cabe señalar respecto a estos datos es que, aplicado el test del chi cuadrado, las diferencias en las frecuencias de las distintas partes del corpus resultan significativas $(\mathrm{x} 2=555828, \mathrm{p}<0.00001)$.

En segundo lugar, las frecuencias obtenidas parecen respaldar la selección de unidades léxicas efectuada, ya que las cifras más altas están en la conversación, y las más bajas están en el discurso formal. Esta distribución se aplica, además, tanto a la ratio total de piezas de léxico informal como al número de unidades léxicas informales diferentes. Puede afirmarse, pues, que como conjunto, las unidades seleccionadas son propias de un registro informal.

Como ya se señaló, las frecuencias más bajas las presenta la muestra de discurso público monológico, con 28 ocurrencias de 15 unidades léxicas distintas, palabras y locuciones, y una ratio del $0,78 \times 1000$. Resulta relevante además que 24 de las 28 unidades localizadas se encuentran en el mismo discurso, el titulado Cangrejos, que presenta una ratio de uso de léxico coloquial muy por encima de la media de esa parte del corpus: 3,04x1000. Analizando con un poco más de detenimiento esta comunicación, se observa que el empleo de términos coloquiales como tío (refiriéndose a una persona cualquiera), o chulo (como sinónimo de bonito), no es el único recurso propio del lenguaje coloquial del que se vale el orador, que utiliza también con frecuencia apelaciones directas a la audiencia o interjecciones, poniendo de manifiesto que la relación entre géneros y registros es de probabilidad, no de estricta dependencia (Briz 2010). Así pues, hay "ejemplares" como este Cangrejos que, por razones que pueden ser de diverso tipo (por ejemplo, una voluntad deliberada del orador de saltarse las normas de la adecuación estilística para resultar más ameno y cercano a su audiencia) no encajan totalmente en lo esperable teniendo en cuenta las circunstancias de enunciación.

En la parte del corpus del discurso político solamente hay un ejemplar de léxico coloquial. Se trata de la palabra chollo, empleada de manera despectiva para hacer referencia a la situación de favoritismos con la que el emisor quiere terminar, en lo que es un caso claro de polifonía textual, ya que al emplear dicho término, el orador adopta de forma intencionalmente crítica la voz de los destinatarios de su crítica:

(20) parece claro / que algunas personas / y grupos económicamente poderosos // consideran que sus intereses particulares // están bien protegidos / con un Gobierno del Partido Popular // y no lo estarían con un Gobierno del Partido Socialista // no ha habido nunca lugar a engaño // desde el primer día / anuncié que si los 
ciudadanos me daban su apoyo en las urnas // una de mis prioridades / como presidente de la Comunidad / sería someter la política de urbanismo / al interés público // combatir la especulación del suelo // considerar la vivienda como un derecho más que como un producto // y estimular por todos los medios legítimos / la oferta / de viviendas dignas / a precios razonables // mensaje / emitido // y mensaje / recibido // si gobierna Simancas / se acabó / el chollo (D_Simancas)

La segunda frecuencia más baja de empleo de léxico coloquial la presenta la

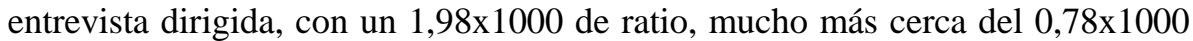
del discurso que del 8,58x1000 de la entrevista libre, en principio un género mucho más cercano estructuralmente, y que sin embargo se encuentra más próxima a las cifras de la conversación, que presenta un 13,17x1000.

Pero las diferencias entre entrevista libre y entrevista dirigida no se reducen a la distancia en las cifras totales, sino que con un análisis más detallado se pueden apreciar discrepancias que van más allá.

En primer lugar, si se hace un análisis por separado de los parlamentos de entrevistadoras e informantes en los dos tipos de entrevista, el panorama resultante muestra diferencias significativas. En la entrevista dirigida el $100 \%$ de las unidades léxicas informales está en los parlamentos de los informantes. Las entrevistadoras no hacen uso ni una sola vez de este tipo de vocabulario. En cambio, en el caso de las entrevistas libres, el habla de las entrevistadoras presenta una ratio del 4,87x1000 de piezas léxicas coloquiales, mayor que el de los informantes en la entrevista dirigida.

Esta diferencia se relaciona, por un lado, con el hecho ya señalado de que la mayoría de las intervenciones de las entrevistadoras de la entrevista dirigida se corresponden con preguntas preparadas que se plantean de modo casi idéntico a todos los informantes, y en cuya formulación se emplea un léxico no marcado estilísticamente. Apenas hay intervenciones espontáneas que se salgan del guion preestablecido.

En las entrevistas libres, en cambio, las intervenciones de las entrevistadoras son mucho más variadas y espontáneas que las de sus homólogas de las entrevistas dirigidas, y en ellas hay lugar para introducir términos como guay, molar o botellón. Las entrevistadoras parecen estar actuando lingüísticamente en consonancia con el ambiente informal que ellas mismas han ido creando en colaboración con los informantes, y ello afecta a todos los planos lingüísticos, incluido el léxico. Al mismo tiempo, el empleo de dicho léxico favorece la 
creación de esa atmósfera cercana, de modo que el empleo de términos y expresiones coloquiales es, a la vez, causa y consecuencia de la situación que se ha establecido entre los interlocutores.

Además, la dinámica interactiva, el hecho de que el diálogo se vaya coconstruyendo de manera colaborativa, y de que las entrevistadoras aprovechen las intervenciones de los informantes para plantear sus preguntas, favorece que aquellas se valgan de términos coloquiales introducidos por sus interlocutores, para seguir profundizando en un mismo tema:

(21) <Informante> hombre / no / a mí me parece normal porque la zona vieja huele / algunas mañanas que <alargamiento> / que alimenta / <fático=E> prácticamente entonces pues tampoco / me parecen muy bien las multas // pero también hay que ponerle a lo otro // luego ya en el <alargamiento> campillo / en la zona del botellón <silencio> es algo diferente / porque al fin y al cabo <risa> es el campo </risa> / <simultáneo>es un parque $/</$ simultáneo $>$

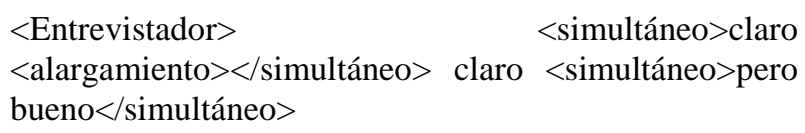

$<$ Informante $><$ simultáneo $>$ y ahí</simultáneo $>$ pues hay <alargamiento> la ley tácita de <alargamiento> / aquí meáis / bebéis / y después os vais de aquí / y no me toquéis / más zonas / si no / plas / <simultáneo>que es <alargamiento> el acuerdo tácito</simultáneo>

<Entrevistador><simultáneo>y lo dejarán</simultáneo> sucio también me imagino con el botellón yo es que <alargamiento> no (EL_SCOM_H13_012)

Otra diferencia fundamental entre los dos tipos de entrevistas reside en las unidades léxicas concretas que se emplean en cada uno y en comparación con las conversaciones. Así, si tomamos las cinco palabras coloquiales más frecuentes de las tres muestras, vemos que, en el caso de la entrevista libre y la conversación, los tres primeros puestos están ocupados por las mismas formas casi en el mismo orden y con frecuencias que en dos de los casos son bastante similares. Además, las otras dos palabras en el cuarto y quinto puesto de la conversación también están en la entrevista libre, aunque en los puestos noveno y decimoprimero. 
Por el contrario, en el caso de la entrevista dirigida no solo no hay ninguna coincidencia en sus palabras más frecuentes con las correspondientes de la conversación, sino que estas presentan en el corpus de entrevista dirigida frecuencias mínimas o nulas: un caso para tío y rollo, y ninguno para guay, jolín y peli.

Tabla 5. Palabras coloquiales más frecuentes en entrevista dirigida, entrevista libre y conversación

\begin{tabular}{|c|c|c|c|c|c|c|}
\hline & Entrevista dirigida & $\mathbf{n}$ & Entrevista libre & $\mathbf{n}$ & Conversación & $\mathbf{n}$ \\
\hline $\mathbf{1}$ & botellón & 3 & rollo & 30 & tío/a & 52 \\
\hline 2 & tele & 3 & guay & 23 & guay & 31 \\
\hline 3 & $\operatorname{coger}^{12}$ & 3 & tío/a & 13 & rollo & 26 \\
\hline 4 & tonto & 3 & botellón & 12 & jolín & 21 \\
\hline 5 & pijo & 3 & $\begin{array}{l}\text { historia } \\
\text { peli (puesto 9) } \\
\text { jolín (puesto 11) }\end{array}$ & 11 & peli & 19 \\
\hline
\end{tabular}

Podría aducirse como argumento para explicar estas diferencias que, en el plano del léxico, y más empleando un corpus relativamente reducido, la frecuencia de las unidades puede estar más relacionada con los temas tratados que con las elecciones estilísticas del hablante. Sin embargo, respecto a esto cabe hacer dos puntualizaciones.

En primer lugar, los temas tratados en las muestras de conversación, entrevista libre y entrevista dirigida son, en conjunto, bastante similares. Se tratan en todos ellos cuestiones relacionadas con la vida cotidiana de personas jóvenes de nivel sociocultural medio-alto: estudios, trabajo, futuro, vacaciones, amigos, pareja, salidas nocturnas, actualidad social, películas...

Por otro lado, y más determinante que lo anterior, la mayoría de las unidades léxicas de tipo coloquial que aparecen en los primeros puestos de la tabla de frecuencias de conversación y entrevista libre no son palabras especializadas temáticamente, sino que pueden emplearse hablando prácticamente de cualquier asunto, ya que tienen un significado extensional muy amplio: algunas son nombres de referencia vaga, como rollo o historia, cuyos posibles referentes pueden ser de muy distinto tipo; otras son vocativos, como tío, o adjetivos como guay que puede aplicarse a cualquier objeto, acción, sensación etc. Una

\footnotetext{
${ }^{12}$ Incluye los casos en que se emplea con dos de las acepciones del DLE que llevan la marca coloquial: "Contraer una enfermedad o empezar a padecer cierto estado físico o anímico" y "Tomar (resolverse a efectuar una acción). Cogió y se fue."
} 
interjección como jolín no está tampoco ligada a ningún tema específico, ya que su función es extraproposicional.

Así, una vez más, puede apuntarse que la entrevista libre se sitúa, en cuanto al uso de léxico coloquial, más cerca de la conversación que la entrevista dirigida, no solamente por las frecuencias totales de este tipo de unidades, sino también por las unidades concretas empleadas en cada caso.

\subsubsection{Léxico malsonante ${ }^{13}$}

Como ya se señaló, el léxico malsonante puede considerarse como el punto extremo del léxico informal. Ya en los años 70, Martín, autor del Diccionario de expresiones malsonantes del español (Martín 1974), relacionaba este tipo de vocabulario con la afectividad y la espontaneidad características del lenguaje coloquial. Más recientemente, las palabras y expresiones malsonantes han sido empleadas como indicadores de informalidad en estudios variacionistas aplicados a corpus de inglés, como el de Quaglio (2009: 109).

En este caso, la guía fundamental para la elaboración de la lista de búsquedas fue la marca malsonante, y en algún caso la marca vulgar del DLE. También se recurrió al Diccionario de la Real Academia Galega, ya que al contener el corpus materiales recogidos en Galicia, se detectaron algunas palabras gallegas, marcadas como vulgar en dicho diccionario, que también fueron incluidas en el estudio.

Cabe señalar, antes de presentar los resultados, que se incluyeron en el estudio todas las palabras malsonantes localizadas, independientemente de su clase morfológica o de su función sintáctica. Así, en la lista hay verbos, adjetivos, sustantivos, interjecciones, etc. Algunos están integrados sintácticamente y otros desempeñan funciones marginales. También se incluyó cualquier tipo de locución o expresión fijada que tuviese entre sus constituyentes un elemento marcado como malsonante.

Se dejaron fuera del estudio, sin embargo, ciertas palabras que aparecían dentro de títulos de películas y nombres de páginas web, ya que constituyen casos en los que el uso del término no responde a una elección lingüística del hablante. Es el caso, por ejemplo, de Cuánto cabrón cuando se refiere al nombre de una página web.

\footnotetext{
${ }^{13}$ Se emplea la denominación de léxico malsonante, siguiendo la terminología del diccionario académico y de la tradición hispánica (Martín 1974) a pesar del evidente sesgo valorativo y en ausencia de otra denominación de consenso para el tipo de unidades que se desean estudiar, ya que otros rótulos como palabras tabú o disfemismos tienen acepciones más restringidas que no engloban todos los casos de interés para el estudio.
} 
Los resultados de frecuencia de léxico malsonante se presentan sintetizados en la Tabla 6 y la Figura $3^{14}$ :

Tabla 6. Frecuencias de términos y expresiones malsonantes (síntesis)

\begin{tabular}{lrrrrr}
\hline & Discurso & & $\begin{array}{l}\text { Entrevista } \\
\text { estructurada }\end{array}$ & Entrevista libre & Conversación \\
\hline TOTAL & 1 & 0 & 89 & 233 \\
Ratio x1000 & 0,028 & 0 & 2,42 & 6,56 \\
\hline
\end{tabular}

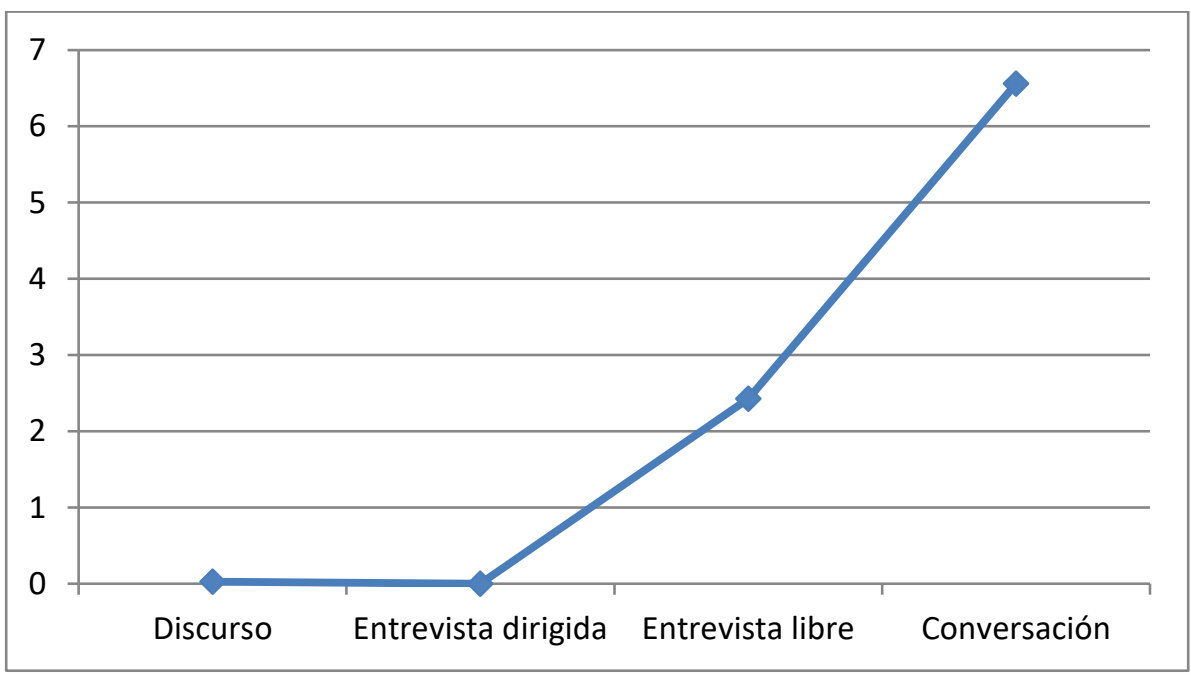

Figura 3. Frecuencias de términos y expresiones malsonantes (ratio x1000)

La distribución que recogen la Tabla 6 y la Figura 3 resulta esperable teniendo en cuenta que esas palabras y expresiones suelen reservarse para las interacciones entre personas con una relación cercana en un contexto relajado, o cuando al menos se busca establecer esa clase de relación. En este sentido, Quaglio \& Biber (2006: 712), trabajando sobre el inglés, apuntan que los "expletivos"15" (término genérico con el que se refieren a las palabras tabú y malsonantes) a menudo se

${ }^{14}$ La lista completa de elementos léxicos malsonantes con sus respectivas frecuencias se encuentra en el Apéndice 3.

${ }^{15}$ Se emplea aquí el término como una traducción del inglés expletive, con valor distinto a los expletivos de la tradición hispánica. 
utilizan para el establecimiento de una atmósfera amistosa entre los hablantes. Carter \& McCarthy (2006: 225) señalan que el uso de este tipo de vocabulario implica que existe una relación de intimidad y confianza entre los interlocutores, de modo que el emisor se siente libre para usarlo. La otra opción es que se establezca una relación hostil y amenazante.

Algunos estudios efectuados sobre corpus de español alcanzan conclusiones semejantes. Zimmermann (2003), por ejemplo, señala cómo algunas palabras malsonantes son empleadas por jóvenes, especialmente de género masculino, como un mecanismo de afiliación de grupo y cohesión identitaria. Bernal Linnersand (2007: 78) en la misma línea, apunta que este tipo de léxico suele aparecer en situaciones prototípicamente coloquiales y de cotidianidad, en las que normalmente existe una relación de amistad entre los participantes. Los resultados de su estudio de corpus se ven apoyados por las conclusiones extraídas de la aplicación de encuestas ${ }^{16}$, que indican que la cercanía y la familiaridad de las relaciones favorecen el uso más frecuente de los términos malsonantes (Bernal Linnersand 2007: 192).

Teniendo en cuenta todo esto, quizá lo primero que llama la atención es que en la muestra de discursos públicos aparezca un caso de palabra malsonante, ya que no se da ninguno de los supuestos anteriores. Se trata del adjetivo jodido inserto dentro de un discurso académico:

\begin{abstract}
RAN \&eh / el tema de la pederastia \{\%alt: pederastía\} / es un tema en la actualidad bastante / peliagudo / bastante / jodido 17:46 \&eh / estamos dentro de un dominio específico / el dominio del sexo / el dominio de las páginas pornográficas / pero / con páginas / que [/] que están buscando un tema \&ile [/] un tema ilegal / contacto con menores 17:59 (D_Premio)
\end{abstract}

El ponente emplea el término en un contexto en el que está hablando de temas realmente delicados, como la pederastia y la pornografía infantil, y lo utiliza para enfatizar la dificultad de trabajar en ámbitos que puedan tener relación con esos temas y añadir un componente de implicación emocional al discurso. De hecho, precisamente la excepcionalidad del uso lo hace en cierta forma más efectivo

\footnotetext{
${ }^{16}$ Los cuestionarios se efectuaron a 18 mujeres y 8 hombres procedentes de Valencia y su área metropolitana, con edades comprendidas entre los 16 y los 25 años, estudiantes universitarios y profesionales de la enseñanza.
} 
comunicativamente. Sin embargo, este tipo de usos no son lo habitual: jodido es el único caso de léxico malsonante localizado en la muestra de discursos públicos. En las entrevistas dirigidas no se detectó ni un solo caso de palabras malsonantes. Teniendo en cuenta la situación y el tipo de relación que se establece de partida entre los interlocutores, bastante distanciada y formal, y que se mantiene de la misma manera a lo largo de todo el intercambio, este hecho resulta lo esperable. En la entrevista libre, sin embargo, aun partiendo de un tipo de interacción en principio similar al de las entrevistas dirigidas y, por tanto, poco propicio para el uso de palabras y expresiones malsonantes, se observa que estas se emplean en una ratio del 2.42×1000. Este hecho se explica porque, en virtud de las técnicas empleadas por las entrevistadoras, se ha ido configurando interactivamente un contexto comunicativo que favorece la informalidad.

Cabe señalar a este respecto que el $100 \%$ de las unidades léxicas malsonantes son empleadas por los informantes: no hay ni un solo caso que se corresponda a una intervención de una entrevistadora. Esto no resulta sorprendente teniendo en cuenta sus circunstancias de enunciación. En primer lugar, a diferencia de los informantes, a los que se les ha garantizado el anonimato, las entrevistadoras se sitúan en un contexto laboral, profesional, en el que son perfectamente identificables, al menos para compañeros e incluso superiores que escucharán (y analizarán) sus intervenciones. Por mucho que de puertas afuera traten de construir un contexto informal y relajado, no pierden la conciencia del tipo de comunicación del que se trata en realidad, sus objetivos y destinatarios, y por tanto de lo que está o no aceptado.

En cuanto al uso que los entrevistados hacen del léxico malsonante, cabe señalar que uno de ellos advierte al inicio de que normalmente dice muchos tacos, y que en el intercambio se va a soltar y hablar como si estuviese en un bar, a lo cual la entrevistadora lo anima efusivamente:

$$
\begin{aligned}
& \text { <Informante><simultáneo>yo me suelto y hago co } \\
& \text { <palabra_cortada> / como si estuviera en un } \\
& \text { bar</simultáneo> } \\
& \text { <Entrevistador><simultáneo>tú suéltate / totalmente / } \\
& \text { totalmente /] sí / pena que no puedes fumar pero } \\
& \text { <alargamiento> (EL_SCOM_H13_012) }
\end{aligned}
$$

De todos modos, esta actitud viene favorecida, sin duda, por el clima de cordialidad y cercanía que la entrevistadora se esfuerza en crear desde el inicio. Resulta muy dudoso que aun definiéndose como malhablado, el informante, 
estudiante de Periodismo y escritor premiado, emplee ese tipo de palabras en contextos percibidos como realmente formales.

Pero además, no es el único que emplea palabras malsonantes, sino que todos los informantes de entrevistas libres se valen en un momento u otro de tales unidades. En la entrevista EL_SCOM_H13_010 se observa que es en los momentos de especial implicación emocional cuando la informante tiende a emplear palabras malsonantes. En concreto, es el relato de una experiencia traumática en un avión el que concentra la mayor parte de ellas:

(24) y entonces la enfermera del aeropuerto se negaba a darme nada // ¿sabes? en plan porque <alargamiento> si no se le caía a ella el pelo / entonces fue un cristo tan grande que después tuvo que ir $\sim$ Emilio a junto de ella en plan $\langle$ cita $>$ mira </cita> / ¿sabes? <cita> soy médico </cita> le enseñó el rollo tal y para darme una mierda de pastilla o sea imagínate /(EL_SCOM_H13_010)

(25) cada vez que me hablaba de coger el billete a mí me subía un rollo por aquí que decía $<$ cita $>$ ¡Dios $\sim$ Emilio! es que yo no no puedo ir / lo siento mucho pero es que no puedo $</$ cita> ¿sabes? <vacilación> / y entonces / ahí ya me acojoné más / (EL_SCOM_H13_010)

(26) yo no voy segura en el avión / no es que <alargamiento> ¿sabes? yo no voy bien / yo iba haciendo respiraciones / todo el viaje / porque si no no podía // <risa > me da en la fila de uno y yo </risa $><c i t a>$ sí hombre pasillo sí $<$ simultáneo $><$ risa/ $>$ ipero joder! $</$ cita $></$ simultáneo $>$

$<$ Entrevistador $>\quad<$ simultáneo $><$ risa/ $>$ pasillo sí</simultáneo $>$ (EL_SCOM_H13_010)

Al hilo de este ejemplo, resulta pertinente señalar un punto en común entre la muestra de entrevista libre y la de conversación: la situación de la forma joder como la unidad más frecuente de la clase. Sin embargo, en cuanto a las frecuencias totales de este tipo de unidades, las diferencias son todavía notables: la entrevista tiene una ratio de $2,42 \times 1000$, frente a la conversación que presenta una ratio de más del doble, 6,56x1000. La prueba del chi cuadrado muestra que, de nuevo, las diferencias en las frecuencias entre los dos corpus son significativas $(\chi 2=69.579)$.

Los resultados en las frecuencias totales parecen indicar, pues, que aunque los informantes de las entrevistas libres empleen palabras malsonantes en ciertas 
circunstancias específicas, a veces en momentos de especial emotividad, en general parece que prefieren valerse de un vocabulario menos marcado. Sin embargo, el mero hecho de que este tipo de formas no esté totalmente ausente, como sucede en la entrevista dirigida, indica que los esfuerzos de las entrevistadoras por desformalizar la entrevista libre sí favorecen la expresión coloquial de los informantes, al menos en este plano.

\section{$5 \quad$ Recapitulación y conclusiones}

El objetivo del trabajo era, a partir de un estudio léxico basado en corpus, aportar datos para la caracterización del registro correspondiente a cuatro géneros orales diferentes, como medida para determinar los efectos de la paradoja del observador en la entrevista sociolingüística y para evaluar la eficacia de las estrategias de desestructuración aplicadas en la entrevista libre.

Aun teniendo en cuenta que el plano léxico es solamente uno más entre otros muchos, parece que se pueden extraer algunas conclusiones.

El factor determinante en la elección del vocabulario por parte de los informantes es, más que la concepción que estos tienen a priori del intercambio, la que se van creando a medida que la interacción avanza, de su grado de formalidad, y del tipo de relación que establecen con su interlocutor.

En las entrevistas dirigidas se configura una situación formal que, en gran parte debido a la estructuración, la diferenciación de roles, el tono impersonal por parte de las entrevistadoras, se mantiene constante durante todo el intercambio. Además, el hecho de que las entrevistadoras limiten en gran medida sus intervenciones a la formulación de preguntas, sin que haya apenas retroalimentación, favorece que las entrevistas se conviertan prácticamente en una sucesión de monólogos independientes. Todo esto explica que la distribución y frecuencia del léxico informal se aproximen mucho a las de un género monológico y planeado como es el discurso público.

La entrevista libre, por el contrario, aun partiendo de unos presupuestos similares, se va transformando mediante el empleo por parte de las entrevistadoras de diferentes estrategias para desestructurar el intercambio y establecer con el interlocutor una relación de cercanía, estrategias que, como se ha constatado, se correlacionan con una mayor frecuencia de léxico coloquial por parte de los informantes, y un uso moderado de términos y expresiones malsonantes. Esta última circunstancia resulta especialmente llamativa, ya que sus contextos de uso están bastante restringidos situacionalmente. Es significativo, además, que las entrevistadoras, que en principio son las que marcan las pautas de la interacción, 
logren la cooperación de sus entrevistados en la construcción de un contexto que favorece el empleo de vocabulario malsonante sin valerse ellas mismas de ese tipo de léxico. Todo ello constituye una manifestación de la libertad de los usuarios en la construcción del contexto, que el género condiciona en buena medida pero no totalmente.

Así pues, en virtud de estos datos, puede concluirse que las estrategias de desestructuración y desformalización son efectivas, lo cual se aprecia en la distancia que los datos de entrevista libre muestran respecto a los obtenidos de la entrevista dirigida y la mayor cercanía con los de la conversación. Esto no quiere decir, sin embargo, que los materiales de entrevista libre sean equivalentes a los conversacionales: a pesar de ciertos paralelismos en las preferencias por cierta terminología coloquial y malsonante, las diferencias en la frecuencia de empleo de estas unidades son todavía significativas.

La segunda conclusión es, pues, que la paradoja del observador sí deja su huella sobre los materiales obtenidos mediante entrevistas, de una manera más o menos marcada dependiendo de las técnicas empleadas, pero en ningún caso los materiales de entrevista son equiparables a los de conversación, al menos en los aspectos estudiados aquí. A pesar de la apariencia conversacional que puedan mostrar algunas entrevistas libres, un análisis profundo del plano léxico revela diferencias claras entre estas y la conversación.

Esta circunstancia resulta comprensible si se considera que las técnicas de la entrevista libre pueden modificar algunas características asociadas a la entrevista tradicional (estructura, roles), intentando acercarla a una conversación pero, aunque puedan tratar de minimizar sus efectos, no pueden cambiar ciertos aspectos del contexto situacional de la entrevista que lo aleja del de la conversación coloquial, como la ausencia de relación previa entre los interlocutores (y lo que ello supone: grado nulo de conocimiento y experiencias compartidas, ausencia de relación afectiva y confianza mutua), las posibles diferencias socioculturales entre ellos, el hecho de que la interacción esté siendo grabada o su carácter transaccional dentro de un contexto académico. La entrevista libre, pues, al menos a la vista de los resultados obtenidos en este estudio, puede señalarse sin duda como un instrumento para minimizar los efectos de la paradoja del observador, pero no para eliminarlos por completo. Queda para investigaciones futuras el análisis comparativo de otros fenómenos, sintácticos, morfológicos o discursivos, para comprobar si las diferencias halladas en el léxico tienen su correspondencia en dichos planos.

El análisis de las técnicas de la entrevista y de los efectos que tienen sobre los materiales obtenidos mediante ellas puede contribuir a diseñar nuevas 
estrategias que logren acercar todavía más su registro al de la conversación coloquial, pero siempre partiendo de que son géneros diferentes y, como tales, no cabe esperar que lleguen a confluir.

\section{Agradecimientos}

Este estudio ha sido realizado en el marco del proyecto de investigación El corpus ESLORA de español oral: enriquecimiento, análisis lingüístico y extracción de recursos (ref. PFFI2017-86379-P), financiado por la Agencia Estatal de Investigación (AEI) y al Fondo Europeo de Desarrollo Regional (FEDER). La autora es investigadora en formación en el grupo de investigación Gramática del español, contratada con cargo a la ayuda para "Consolidación e estruturación de Grupos con Potencial de Crecemento 2017" de la Consellería de Cultura, Educación e Ordenación Universitaria de la Xunta de Galicia (ref. ED431B 2017/39).

\section{Referencias bibliográficas}

Bernal Linnersand, M. 2007. Categorización sociopragmática de la cortesía y de la descortesía. Un estudio de la conversación coloquial española. Tesis doctoral, Universidad de Estocolmo.

Biber, D. 1988. Variation across Speech and Writing. Cambridge: Cambridge University Press.

Biber, D., Conrad, S. \& Leech G. N. 2002. Longman student grammar of spoken and written English. Harlow, Essex: Longman.

Briz, A. 1998. El español coloquial en la conversación. Esbozo de pragmagramática. Barcelona: Ariel Lingüística.

Briz, A. 2000. El análisis de un texto oral coloquial. En A. Briz \& Grupo Val.Es.Co. (eds), ¿Cómo se comenta un texto coloquial? Barcelona: Ariel-Practicum, 29-48.

Briz. A. 2002. El léxico coloquial en la conversación. Revista Textos [versión electrònica] 31. https://www.grao.com/es/producto/el-lexico-coloquial-en-la-conversacion (acceso 6 de septiembre de 2018).

Briz, A. 2010. El registro como centro de la variedad situacional. Esbozo de la propuesta del grupo Val.Es.Co. sobre las variedades diafásicas. En I. Fonte \& L. Rodríguez Alfano (comp), Perspectivas dialógicas en estudios del lenguaje. México: Universidad Autónoma de Nuevo León, 21-56.

Carter, R. \& McCarthy, M. 2006. Cambridge grammar of English: A comprehensive guide. Cambridge: Cambridge University Press.

Cooper, T. C. 2001. "Does is suck"? Or "is it for the birds?" Native speaker judgement of slang expressions. American speech, 76: 62-78.

De Benito Moreno, C. \& Estrada Erráez, A. 2017. Introducción. Si Alvar levantara la cabeza: cómo tratar con informantes virtuales. En C. De Benito Moreno \& A. Estrada Arráez (eds), 
Variación lingüística e internet: cayendo en la red. Madrid/Frankfurt: Iberoamericana Vervuert, 7-17.

Domínguez Mujica, C. L. 2005. Sintaxis de la lengua oral. Mérida: Universidad de los Andes. Fernández Juncal, M. C. 2005. Corpus de habla culta de Salamanca (CHCS). Burgos: Fundación Instituto Castellano y Leonés de la Lengua.

Fitch, R. 2011. Diccionario de coloquialismos y téminos dialectales del español. Barcelona: Arco-Libros.

Gumperz, J. J. 1982. Discourse Strategies. Cambridge: Cambridge University Press.

Gumperz, J. J. 1992. Contextualization Revisited. En P. Auer \& A. Di Luzio (eds), The Contextualization of Language. Amsterdam: John Benjamins, 39-53.

Hernández Campoy, J. M. \& Almeida, M. 2005. Metodología de la investigación sociolingüística. Granada: Comares.

Koch, P. \& Oesterreicher, W. 1990. Lengua hablada en la Romania: español, francés, italiano. Madrid 2007: Gredos. Versión española de A. López Serena del original alemán Gesprochene Sprache in der Romania: Französisch, Italienisch, Spanisch. Tubinga: Max Niemeyer.

Labov, W. 1972. Some principles of linguistic methodology. Language in Society I: 97-120.

Labov, W. 1984. Field Methods of the Project on Linguistic Change and Variation. En J. Baugh \& J. Sherzer (eds), Language in Use: Readings in Sociolinguistics. Englewood Cliffs, NJ: Prentice Hall, 28-66.

López Morales, H. 1994. Métodos de investigación lingüística. Salamanca: Ediciones Colegio de España.

López Serena, A. 2007. Oralidad y escrituralidad en la recreación literaria del español coloquial. Madrid: Gredos.

Martín Martín, J. 1974. Diccionario de expresiones malsonantes del español: léxico descriptivo. Madrid: Istmo.

Milroy, L., \& Gordon, M., 2003. Sociolinguistics: Method and Interpretation. Oxford: Blackwell.

Moreno Fernández, F. 2001. La entrevista sociolingüística. Esquemas de perspectivas. Linred, Lingüística en la red, Monográfico: I Jornadas de Lengua y Comunicación. Marcadores Discursivos. http://www.linred.es/numero9_monografico1_Art6.html (acceso 24 de abril, 2017).

Moya Corral, J. A. (coord) 2007. El español hablado en Granada. Corpus oral para su estudio sociolingüístico. I Nivel de estudios alto. Granada: EUG.

Moya Corral, J. A. (coord) 2008. El español hablado en Granada II. Corpus oral para su estudio sociolingüístico. Nivel de estudios medio. Granada: EUG.

Narbona Jiménez, A. 1988[1989]. Sintaxis coloquial, problemas y métodos. LEA, X/I: 81-106. Reproducido en Sintaxis española: nuevos y viejos enfoques, 1989, 171-203.

Parodi, G. 2010. La organización retórica del género manual a través de cuatro disciplinas: ¿cómo se comunica y difunde la ciencia en diferentes contextos universitarios?. Boletín de Lingüística [en línea] XXII (Enero-Junio). http://www.redalyc.org/articulo.oa?id=34715897003 (acceso 27 de agosto de 2018).

Pitkowski, E. F. 2010. La entrevista sociolingüística y su valor como método de investigación. Trabajo de fin de grado, Université de Montréal.

PRESEEA 2003. Metodología del "Proyecto para el Estudio Sociolingüístico del Español de España y de América" (PRESEEA). Versión revisada - Octubre 2003. 
http://preseea.linguas.net/Portals/0/Metodologia/METODOLOG\%C3\%8DA\%20PRESE EA.pdf (acceso 3 de septiembre de 2018).

Quaglio, P. \& Biber, D. 2006. The Grammar of Conversation. En B. Aarts \& A. McMahon (eds), The Handbook of English Linguistics. Malden: Wiley-Blackwell, 692-723.

Quaglio, P. 2009. Television dialogue: the sitcom "Friends" vs. natural conversation. Amsterdam: John Benjamins.

Recalde, M. \& Vázquez Rozas, V. 2009. Problemas metodológicos en la formación de corpus orales. En P. Cantos Gómez \& A. Sánchez Pérez (eds), A Survey on Corpus-based Research / Panorama de investigaciones basadas en corpus. Murcia: AELINCO, 37-49. https://www.um.es/lacell/aelinco/contenido/pdf/4.pdf.

Sanmartín, J. 2000. La creación léxica (I). Neologismos semánticos: las metáforas de cada día. En A. Briz \& Grupo Val.Es.Co. (eds), ¿Cómo se comenta un texto coloquial? Barcelona: Ariel-Practicum, 125-142.

Silva-Corvalán, C. 1989. Sociolingüística: Teoría y análisis. Madrid: Alhambra.

Simon-Vandenbergen AM. 1986. Register Theory and Communicative Teaching. En F. Lowenthal \& F. Vandamme F. (eds), Pragmatics and Education. Boston: Springer, 143156.

Vázquez Veiga, N. 2003. Marcadores discursivos de recepción. Santiago de Compostela: Universidade de Santiago de Compostela.

Vida Castro, M. (ed) 2007. El español hablado en Málaga. Málaga: Editorial Sarriá.

Wolfran, W. \& Fasold, R. W. 1997. Field Methods in the Study of Social Dialects. En N. Coupland \& A. Jaworski (eds), Sociolinguistics. A reader and coursebook. Basingstoke: Palgrave, 89-115.

Wolfson, N. 1976. Speech events and natural speech: some implications for sociolinguistic methodology". Language in Society, 5(2): 189-209.

Wolfson, N. 1997. Speech Events and Natural Speech. En N. Coupland \& A. Jaworski (eds), Sociolinguistics. A reader and coursebook. Basingstoke: Palgrave, 116-125.

Zimmermann, K. 2003. Constitución de la identidad y anticortesía verbal entre jóvenes masculinos hablantes de español. En D. Bravo (ed), La perspectiva no etnocentrista de la cortesía: identidad sociocultural de las comunidades hispanohablantes. Estocolmo: Universidad de Estocolmo, 47-59.

\section{Corpus:}

ESCEGRA: Estudio Sociolingüístico del Corpus de Español de Granada (ESCEGRA), Universidad de Granada.

ESLORA: Corpus para el estudio del español oral <http://eslora.usc.es〉, versión 1.1 de marzo de 2018, ISSN: 2444-1430.

MAVIR: Antonio Moreno Sandoval, Leonardo Campillos Llanos. 2012. "MAVIR: a corpus of spontaneous formal speech in Spanish and English".

Recursos web:

Coloquialmente. http://coloquialmente.com/es (acceso 10 de abril, 2017)

Congreso de los diputados. Intervenciones. http://www.congreso.es/portal/page/portal/Congreso/Congreso/Intervenciones (acceso 25 de enero, 2017) 
Diccionario Real Academia Galega, 2012. https://academia.gal/dicionario (acceso 10 de abril, 2017)

Jergas de habla hispana. http://www.jergasdehablahispana.org/ (acceso 10 de abril, 2017)

Qué significado. https://quesignificado.com/ (acceso 10 de abril, 2017)

Diccionario de la lengua española (22.a ed.). Real Academia Española. (2001). http://www.rae.es/rae.html (acceso 10 de abril, 2017)

The Free Dictionary. https://www.thefreedictionary.com/ (acceso 10 de abril, 2017)

Wiktionary, Wikcionario. https://es.wiktionary.org/wiki/Wikcionario:Portada (acceso 10 de abril, 2017)

Wordreference español. http://www.wordreference.com/definicion/ (acceso 10 de abril, 2017) 


\section{Apéndice 1}

\section{Convenciones de transcripción empleadas en los ejemplos seleccionados}

Se respetaron las normas de transcripción de los corpus de origen, introduciendo ligeros cambios para adaptarlas a las características y objetivos del trabajo.

No se han utilizado en ningún caso letras mayúsculas por razones de puntuación ni tampoco al inicio de turno. Tampoco se emplean nunca coma, punto, punto y coma, dos puntos, puntos suspensivos, comillas ni guion.

\section{Entrevista libre}

\section{Corpus ESLORA}

Adaptación de las convenciones del proyecto ESLORA, versión 1.1 de marzo de 2018 (<http://eslora.usc.es/guide_oral_tags〉, acceso 30 de agosto de 2018)

\begin{tabular}{|c|c|}
\hline$<$ Informante $><$ Entrevistador $>$ & Identificación de hablantes \\
\hline$<$ risa/> & Risa de un hablante \\
\hline$\langle$ risa $\rangle\langle/$ risa $\rangle$ & Segmento pronunciado entre risas \\
\hline <alargamiento> & $\begin{array}{l}\text { Aumento de cantidad que afecta a algún sonido de la } \\
\text { palabra marcada }\end{array}$ \\
\hline$<$ fático $=>$ & $\begin{array}{l}\text { Sustituye una señal fónica no transcribible que } \\
\text { funciona como marcador de recepción. Después del } \\
\text { signo = se añade la inicial del hablante que emite el } \\
\text { fático }\end{array}$ \\
\hline$\langle$ gl $|\langle/$ gl $\mid\rangle$ & Segmento en lengua gallega \\
\hline$<$ ininteligible > & $\begin{array}{l}\text { Sustituye un fragmento no comprensible y por tanto } \\
\text { no transcrito }\end{array}$ \\
\hline <énfasis $></$ énfasis> & $\begin{array}{l}\text { Segmento de pronunciación especialmente } \\
\text { acentuada }\end{array}$ \\
\hline <ruido=> & Tras el signo $=$ se especifica el tipo de ruido \\
\hline$\langle$ cita $\rangle</$ cita $>$ & Segmento en estilo directo \\
\hline$\langle$ palabra_cortada $>$ & Acompaña al fragmento de una palabra \\
\hline$<$ vacilación> & $\begin{array}{l}\text { Sustituye fragmentos similares a palabras cortadas } \\
\text { pero imposibles de transcribir }\end{array}$ \\
\hline$<$ simultáneo $></$ simultáneo $>$ & Segmento de habla solapada \\
\hline / & Pausa \\
\hline // & Pausa larga menor de un segundo \\
\hline <silencio> & Pausa de más de un segundo \\
\hline$\sim$ & $\begin{array}{l}\text { Acompaña un nombre propio que ha sido cambiado } \\
\text { para preservar el anonimato de los hablantes }\end{array}$ \\
\hline
\end{tabular}




\begin{tabular}{ll}
\hline$i !$ & Enunciado exclamativo \\
$i ?$ & Enunciado interrogativo \\
\hline
\end{tabular}

\section{Entrevista dirigida}

\section{Corpus ESCEGRA}

Adaptación de las convenciones de Moya Corral (2007)

\begin{tabular}{|c|c|}
\hline E: & Entrevistador \\
\hline I: & Informante \\
\hline ¿? & Enunciado interrogativo \\
\hline / & Pausa funcional \\
\hline$/ /$ & Pausa breve \\
\hline$\langle(:)\rangle$ & Alargamiento fónico \\
\hline <ruido = " "/> & Ruido, con especificación de tipo y hablante \\
\hline $\begin{array}{l}\text { <simultáneo> } \\
\text { ultáneo> }\end{array}$ & Solapamiento discursivo \\
\hline$\langle(\mathbf{m}:)\rangle$ & Apoyo discursivo \\
\hline$\langle$ fático $=$ afirmación $=|>$ & Aseveración fática \\
\hline
\end{tabular}

\section{Corpus de habla culta de Salamanca, CHCS (Versión CORPES XXI)}

$\mathrm{Se}$ siguieron las convenciones empleadas en el CORPES XXI (<http://web.frl.es/CORPES/org/publico/pages/ayuda/codOral.view〉, fecha de consulta 29-08-2018)

\begin{tabular}{ll}
\hline$/$ & Pausa breve \\
$/ /$ & Pausa larga, de menos de un segundo \\
$<$ fático hb ="'"/> & Sustituye una señal fónica no transcribible que \\
& funciona como marcador de recepción. Después del \\
& signo = se añade la inicial del hablante que emite el \\
& fático \\
& Indicación de un ruido que no se solapa con el habla de \\
& ningún participante. Se especifica el tipo de ruido en el \\
& valor del atributo 'desc' \\
& Segmento de habla solapada \\
\hline simultáneo $></$ simultáneo $>$
\end{tabular}




\section{Discurso público \\ Congreso de los diputados}

\begin{tabular}{ll}
\hline$/$ & pausa breve \\
$/ /$ & pausa larga, menor de un segundo \\
\hline
\end{tabular}

\section{Corpus MAVIR}

Adaptación de las convenciones de transcripción del corpus MAVIR (<http://cartago.lllf.uam.es/static/mavir/ConvencionesMAVIR.pdf $>, \quad$ acceso $30 / 08 / 2018)$

\begin{tabular}{ll}
\hline Tres letras mayúsculas & Identificación de hablantes \\
& Separa unidades tonales que no tienen autonomía sintáctica \\
& ni semántica (una palabra o sintagma). La entonación suele \\
& ser ascendente, porque la oración está inacabada \\
& Separan dentro del discurso aquellas unidades que tienen \\
& autonomía oracional y semántica. Indica una pausa más \\
& marcada, después de la cual se prosigue la unidad \\
& informativa \\
& Debido a un falso inicio, el hablante repite un término o un \\
& sintagma, o lo reconstruye si se ha equivocado \\
& Alargamiento vocálico o consonántico a final de palabra \\
& Precede a una palabra no terminada de pronunciar (debido \\
& a una autocorrección, una autointerrupción...), o a una \\
\& & palabra agramatical cuya forma normativa no se puede \\
& reconstruir, o no parece apropiado hacerlo \\
& Apoyos vocálicos \\
& Indica cualquier error de pronunciación o palabra \\
& agramatical. Se transcribe correctamente la palabra y se \\
& translitera el sonido entre corchetes, indicado por la marca \\
\%ealt \&ah \&mm &
\end{tabular}




\section{Apéndices 2 y 3}

Frecuencias de léxico coloquial (desglosado) y Frecuencias de términos y expresiones malsonantes (desglosado)

\section{Léxico coloquial}

\begin{tabular}{|c|c|c|c|c|}
\hline & Discurso & $\begin{array}{l}\text { Entrevista } \\
\text { dirigida }\end{array}$ & $\begin{array}{l}\text { Entrevista } \\
\text { libre }\end{array}$ & Conversación \\
\hline \multicolumn{5}{|l|}{ Unidades léxicas simples } \\
\hline animalada & 0 & 0 & 0 & 5 \\
\hline apañado (bien aprovechado) & 0 & 0 & 1 & 0 \\
\hline $\begin{array}{l}\text { apretón (movimiento del } \\
\text { vientre) }\end{array}$ & 0 & 0 & 1 & 0 \\
\hline armario (persona fuerte) & 0 & 0 & 0 & 1 \\
\hline baboso & 0 & 1 & 0 & 0 \\
\hline bailoteo & 0 & 0 & 1 & 0 \\
\hline batiburrillo & 0 & 1 & 0 & 0 \\
\hline bicho & 0 & 1 & 1 & 2 \\
\hline birria & 0 & 1 & 0 & 0 \\
\hline botellón & 0 & 3 & 12 & 1 \\
\hline burrada & 0 & 0 & 0 & 2 \\
\hline buscavidas & 0 & 0 & 1 & 0 \\
\hline cabrearse/cabreo & 0 & 0 & 0 & 3 \\
\hline caca & 0 & 0 & 0 & 1 \\
\hline cacharro & 0 & 0 & 0 & 1 \\
\hline cacho & 0 & 0 & 0 & 5 \\
\hline cani & 0 & 0 & 0 & 2 \\
\hline cargar (irritar) & 0 & 0 & 1 & 0 \\
\hline $\operatorname{cargar}(s e)$ (algo) & 1 & 0 & 0 & 2 \\
\hline chao & 0 & 0 & 1 & 6 \\
\hline chapón & 0 & 0 & 0 & 1 \\
\hline chisme & 0 & 0 & 1 & 1 \\
\hline chollo & 1 & 0 & 0 & 0 \\
\hline choni & 0 & 0 & 0 & 1 \\
\hline
\end{tabular}




\begin{tabular}{|c|c|c|c|c|}
\hline chorrada & 0 & 0 & 1 & 1 \\
\hline chufla & 0 & 0 & 0 & 1 \\
\hline chulo/a & 3 & 0 & 1 & 2 \\
\hline chungo/a & 0 & 0 & 2 & 7 \\
\hline chupar (de) & 0 & 0 & 1 & 0 \\
\hline chupi & 0 & 0 & 0 & 1 \\
\hline churro & 0 & 2 & 0 & 0 \\
\hline chuta & 0 & 0 & 1 & 0 \\
\hline chutarse & 0 & 0 & 0 & 1 \\
\hline ciscar & 0 & 0 & 0 & 1 \\
\hline clavar (cobrar caro) & 0 & 0 & 0 & 2 \\
\hline cocido & 0 & 0 & 1 & 0 \\
\hline coger (una enfermedad; coger & 1 & 3 & 1 & 11 \\
\hline \multicolumn{5}{|l|}{$\mathbf{y}+v e r b o)$} \\
\hline colega & 0 & 0 & 2 & 3 \\
\hline comerse & 0 & 0 & 2 & 0 \\
\hline coña & 0 & 0 & 1 & 2 \\
\hline costo & 0 & 1 & 0 & 0 \\
\hline cristo (lio) & 0 & 0 & 3 & 0 \\
\hline cubata & 0 & 0 & 0 & 3 \\
\hline cucada & 0 & 0 & 0 & 1 \\
\hline currar & 0 & 0 & 5 & 0 \\
\hline cutre & 0 & 1 & 1 & 3 \\
\hline desfase & 0 & 0 & 0 & 1 \\
\hline despiporre & 0 & 0 & 0 & 2 \\
\hline engancharse & 3 & 0 & 2 & 1 \\
\hline enrollarse (hablar mucho) & 0 & 0 & 3 & 0 \\
\hline entrarle a alguien & 0 & 0 & 0 & 1 \\
\hline espachurrar & 0 & 1 & 0 & 0 \\
\hline$e x$ & 0 & 0 & 0 & 2 \\
\hline fastidiar & 2 & 0 & 2 & 0 \\
\hline flipar & 0 & 0 & 3 & 17 \\
\hline follón & 0 & 1 & 0 & 0 \\
\hline fondón & 0 & 0 & 0 & 2 \\
\hline
\end{tabular}




\begin{tabular}{|c|c|c|c|c|}
\hline forrarse & 0 & 0 & 1 & 0 \\
\hline $\begin{array}{l}\text { gordo (muy grande, fuera de } \\
\text { lo corriente) }\end{array}$ & 1 & 2 & 0 & 2 \\
\hline guapo (aplicado a objetos) & 0 & 0 & 0 & 2 \\
\hline guarro/a & 0 & 0 & 0 & 1 \\
\hline guay & 0 & 0 & 23 & 31 \\
\hline gusanillo & 0 & 1 & 0 & 0 \\
\hline historia (mentira, enredo) & 0 & 0 & 11 & 4 \\
\hline incordio & 0 & 0 & 1 & 0 \\
\hline jobar & 0 & 0 & 3 & 0 \\
\hline jolín/jolines & 0 & 0 & 5 & 21 \\
\hline largarse & 0 & 0 & 0 & 1 \\
\hline liarse & 0 & 0 & 0 & 2 \\
\hline macho & 0 & 0 & 0 & 6 \\
\hline mamá & 0 & 0 & 2 & 6 \\
\hline mami & 0 & 0 & 0 & 1 \\
\hline mates & 0 & 0 & 0 & 1 \\
\hline mazarse & 0 & 0 & 0 & 10 \\
\hline menda & 0 & 0 & 1 & 0 \\
\hline mítico & 0 & 0 & 4 & 8 \\
\hline mogollón & 0 & 0 & 3 & 0 \\
\hline molar & 0 & 0 & 4 & 18 \\
\hline $\begin{array}{l}\text { mono (síndrome de } \\
\text { abstinencia) }\end{array}$ & 0 & 1 & 0 & 0 \\
\hline montón, montones, montonazo & 4 & 1 & 5 & 7 \\
\hline morirse (de o por) & 0 & 0 & 3 & 0 \\
\hline mosqueado & 0 & 0 & 1 & 0 \\
\hline movida & 0 & 0 & 1 & 4 \\
\hline movida (jaleo) & 0 & 0 & 0 & 1 \\
\hline negro (enfadado o irritado) & 0 & 0 & 3 & 0 \\
\hline ostras & 0 & 0 & 0 & 8 \\
\hline poner (excitar) & 0 & 0 & 1 & 0 \\
\hline pamplinas & 0 & 1 & 0 & 0 \\
\hline panchito & 0 & 0 & 0 & 1 \\
\hline
\end{tabular}




\begin{tabular}{|c|c|c|c|c|}
\hline papá & 0 & 0 & 0 & 3 \\
\hline papi & 0 & 1 & 0 & 1 \\
\hline parida & 0 & 0 & 0 & 2 \\
\hline pasada & 0 & 0 & 1 & 0 \\
\hline pasar de & 0 & 1 & 0 & 4 \\
\hline pasota & 0 & 0 & 1 & 0 \\
\hline pasta (dinero) & 0 & 0 & 7 & 3 \\
\hline pavo (chico) & 0 & 0 & 1 & 2 \\
\hline pavo (euro) & 0 & 0 & 0 & 5 \\
\hline pedazo de & 0 & 0 & 1 & 0 \\
\hline peliagudo & 1 & 0 & 1 & 1 \\
\hline peña (gente) & 0 & 0 & 0 & 1 \\
\hline peta & 0 & 2 & 0 & 0 \\
\hline petarse/petado & 0 & 0 & 0 & 3 \\
\hline pijo & 0 & 3 & 0 & 7 \\
\hline pila de & 0 & 0 & 0 & 1 \\
\hline $\begin{array}{l}\text { pillar (sorprender a alguien, } \\
\text { contraer una enfermedad) }\end{array}$ & 0 & 0 & 0 & 4 \\
\hline pimplar & 0 & 0 & 0 & 1 \\
\hline pinchar (con alguien) & 0 & 0 & 0 & 1 \\
\hline pipear & 0 & 0 & 1 & 0 \\
\hline pirarse & 0 & 0 & 4 & 0 \\
\hline quemar (disgustar) & 0 & 1 & 1 & 0 \\
\hline rajar (criticar) & 0 & 0 & 9 & 3 \\
\hline rallar (molestar) & 0 & 0 & 0 & 2 \\
\hline $\operatorname{rayar}(\mathrm{se})$ & 0 & 0 & 1 & 5 \\
\hline rollo & 0 & 1 & 30 & 26 \\
\hline $\begin{array}{l}\text { rollo (discurso largo pesado y } \\
\text { aburrido) }\end{array}$ & 0 & 0 & 1 & 0 \\
\hline soltar (decir algo) & 0 & 0 & 3 & 0 \\
\hline sonar (ser conocido) & 0 & 0 & 4 & 5 \\
\hline sudaca & 0 & 0 & 1 & 0 \\
\hline timbrar (tocar el timbre) & 0 & 0 & 0 & 2 \\
\hline tío/a & 4 & 1 & 13 & 52 \\
\hline
\end{tabular}




\begin{tabular}{|c|c|c|c|c|}
\hline tipo (persona) & 0 & 0 & 3 & 5 \\
\hline tirarse (a alguien) & 0 & 0 & 0 & 1 \\
\hline tonto & 3 & 3 & 0 & 10 \\
\hline torta (bofetada) & 0 & 0 & 0 & 2 \\
\hline tragarse & 0 & 0 & 1 & 1 \\
\hline $\begin{array}{l}\text { una patata (cosa de poca } \\
\text { calidad) }\end{array}$ & 0 & 0 & 0 & 1 \\
\hline yanqui & 0 & 0 & 1 & 0 \\
\hline yonqui & 0 & 0 & 3 & 0 \\
\hline Palabras acortadas & 0 & 0 & 0 & 0 \\
\hline bac (bachillerato) & 0 & 0 & 0 & 1 \\
\hline bici & 0 & 0 & 2 & 0 \\
\hline boli & 0 & 1 & 0 & 0 \\
\hline bus & 0 & 0 & 2 & 1 \\
\hline cole & 0 & 0 & 4 & 0 \\
\hline mili & 0 & 1 & 0 & 0 \\
\hline peli & 0 & 0 & 6 & 19 \\
\hline profe & 0 & 0 & 0 & 4 \\
\hline progre & 0 & 0 & 1 & 0 \\
\hline tele & 0 & 3 & 6 & 5 \\
\hline teleco & 0 & 1 & 0 & 0 \\
\hline \multicolumn{5}{|l|}{ Unidades fraseológicas } \\
\hline (ir) a mi bola, a nuestra bola & 0 & 0 & 2 & 1 \\
\hline a pata & 0 & 0 & 0 & 1 \\
\hline a pelo & 0 & 0 & 0 & 1 \\
\hline ancha es Castilla & 0 & 0 & 1 & 0 \\
\hline $\begin{array}{l}\text { arrimando/refregando } \\
\text { cebolleta }\end{array}$ & 0 & 0 & 0 & 2 \\
\hline bichos raros & 0 & 0 & 0 & 1 \\
\hline borrón y cuenta nueva & 0 & 0 & 1 & 0 \\
\hline caérsele a alguien el pelo & 0 & 0 & 2 & 0 \\
\hline cerrarse en banda & 0 & 0 & 1 & 0 \\
\hline como quien dice & 0 & 0 & 2 & 1 \\
\hline
\end{tabular}




\begin{tabular}{|c|c|c|c|c|}
\hline con todo el morro & 0 & 0 & 1 & 0 \\
\hline culo inquieto & 0 & 0 & 2 & 0 \\
\hline dar alguien una vuelta & 0 & 1 & 0 & 0 \\
\hline dar corte algo a alguien & 0 & 0 & 0 & 1 \\
\hline dar vueltas a algo & 0 & 1 & 6 & 0 \\
\hline darle a alguien la gana & 1 & 4 & 2 & 4 \\
\hline darle algo a alguien & 0 & 0 & 0 & 3 \\
\hline de narices & 0 & 0 & 1 & 0 \\
\hline de toda la vida & 0 & 2 & 6 & 4 \\
\hline echar un cable & 0 & 1 & 0 & 0 \\
\hline en plata & 0 & 0 & 2 & 0 \\
\hline entrar o pasar por el aro & 0 & 0 & 1 & 0 \\
\hline estar alguien en las últimas & 0 & 0 & 1 & 0 \\
\hline estar como un cencerro & 0 & 0 & 1 & 0 \\
\hline estar como un tren & 0 & 0 & 0 & 1 \\
\hline estar hasta el gorro & 0 & 0 & 4 & 0 \\
\hline estar hasta el moño & 0 & 0 & 1 & 0 \\
\hline pedir algo a gritos & 0 & 1 & 0 & 0 \\
\hline hablar por los codos & 0 & 0 & 1 & 0 \\
\hline hacer el cabra & 0 & 1 & 0 & 0 \\
\hline hacer la pelota & 0 & 1 & 0 & 0 \\
\hline hacer tilín & 0 & 0 & 0 & 2 \\
\hline ir a $(m i, t u, s u . .$.$) rollo$ & 0 & 1 & 0 & 0 \\
\hline irse a la calle & 0 & 1 & 0 & 0 \\
\hline irse la pinza & 0 & 1 & 0 & 0 \\
\hline írsele a alguien la olla & 0 & 0 & 1 & 1 \\
\hline la cuenta de la vieja & 1 & 0 & 0 & 0 \\
\hline la madre que te parió & 0 & 0 & 0 & 1 \\
\hline liarla & 0 & 0 & 0 & 1 \\
\hline más claro que el agua & 0 & 1 & 0 & 0 \\
\hline meter caña & 0 & 0 & 1 & 0 \\
\hline meter la pata & 0 & 0 & 2 & 0 \\
\hline muerto de asco/morirse de asco & 0 & 0 & 1 & 1 \\
\hline
\end{tabular}




\begin{tabular}{|c|c|c|c|c|}
\hline ni de coña & 0 & 0 & 1 & 3 \\
\hline ni Dios & 0 & 0 & 1 & 1 \\
\hline ni loco & 0 & 2 & 0 & 0 \\
\hline no hay dios que & 0 & 0 & 0 & 1 \\
\hline no tragar a alguien o algo & 0 & 0 & 1 & 0 \\
\hline pagar el pato & 0 & 1 & 0 & 0 \\
\hline para nada & 1 & 0 & 2 & 1 \\
\hline pasar el rato & 0 & 0 & 0 & 1 \\
\hline patatín patatán & 0 & 0 & 2 & 0 \\
\hline $\begin{array}{l}\text { ponérsele a alguien los pelos de } \\
\text { punta }\end{array}$ & 0 & 0 & 1 & 0 \\
\hline por algo & 0 & 1 & 0 & 2 \\
\hline por los cerros de Úbeda & 0 & 0 & 1 & 1 \\
\hline $\begin{array}{l}\text { que (me, te, le etc.) quiten lo } \\
\text { bailado }\end{array}$ & 0 & 0 & 1 & 0 \\
\hline$q u e ́ v a$ & 0 & 1 & 0 & 8 \\
\hline qué/cómo demonios & 1 & 0 & 1 & 0 \\
\hline quedarse alguien frito & 0 & 1 & 0 & 0 \\
\hline quedarse planchado/a & 0 & 0 & 0 & 1 \\
\hline rascarse alguien las narices ) & 0 & 0 & 1 & 0 \\
\hline romperse la cabeza & 0 & 1 & 0 & 0 \\
\hline saltarse a la torera & 0 & 0 & 1 & 0 \\
\hline ser el último mono & 0 & 1 & 0 & 0 \\
\hline ser uña y carne & 0 & 0 & 1 & 0 \\
\hline sin comerlo ni beberlo & 0 & 0 & 1 & 0 \\
\hline sonar a chino & 0 & 0 & 1 & 0 \\
\hline tarde o temprano & 0 & 0 & 1 & 0 \\
\hline tela marinera & 0 & 0 & 0 & 1 \\
\hline $\begin{array}{l}\text { tocarle (romperle) a alguien las } \\
\text { narices }\end{array}$ & 0 & 0 & 2 & 0 \\
\hline toda la vida & 0 & 2 & 10 & 2 \\
\hline todo el día & 0 & 6 & 9 & 2 \\
\hline TOTAL & 28 & 73 & 315 & 468 \\
\hline RATIO x1000 & 0,78 & 1,98 & 8,58 & 13,17 \\
\hline
\end{tabular}




\section{Términos y expresiones malsonantes}

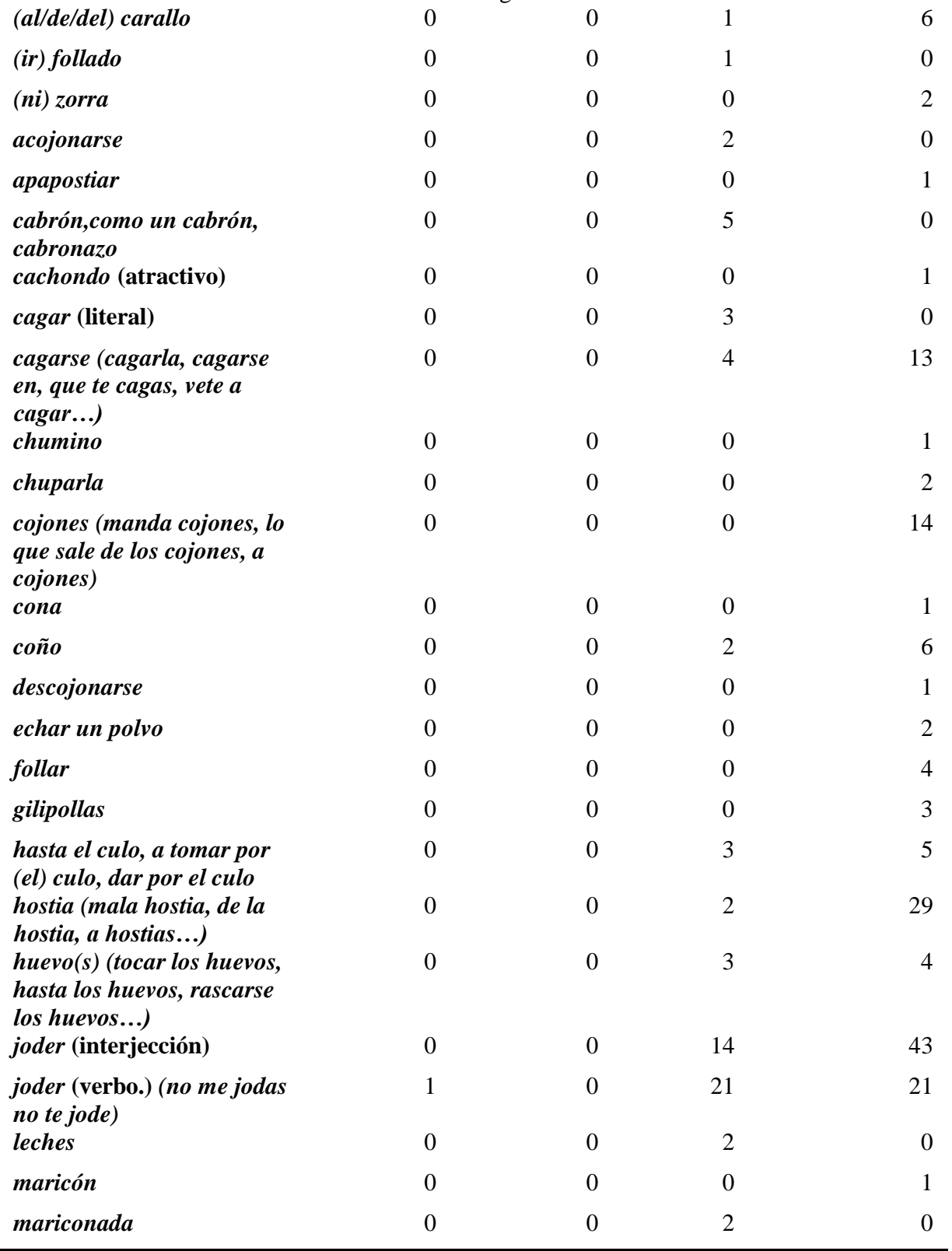

Discurso Entrevista Entrevista Conversación dirigida 


\begin{tabular}{lrrrr}
\hline meada & 0 & 0 & 2 & 0 \\
mear & 0 & 0 & 6 & 3 \\
mierda, merda & 0 & 0 & 5 & 29 \\
pedo (borrachera) & 0 & 0 & 0 & 1 \\
polla (pollas, una polla & como una olla) & 0 & 0 & 5 \\
puta & 0 & 0 & 5 & 4 \\
putada & 0 & 0 & 0 & 2 \\
putear & 0 & 0 & 4 & 0 \\
puteo & 0 & 0 & 1 & 0 \\
puto/a (puta madre, ni puta & 0 & 0 & 1 & 26 \\
idea...) & 0 & 0 & 0 & 1 \\
se la pela & 0 & 0 & 0 & 2 \\
se la suda & $\mathbf{1}$ & $\mathbf{0}$ & $\mathbf{8 9}$ & $\mathbf{2 3 3}$ \\
\hline TOTAL & $\mathbf{0 , 0 2 8}$ & $\mathbf{0}$ & $\mathbf{2 , 4 2}$ & $\mathbf{6 , 5 6}$ \\
Ratio & & & & \\
\hline
\end{tabular}

